\title{
Combined Targeting of AKT and mTOR Synergistically Inhibits Formation of Primary Colorectal Carcinoma Tumouroids In Vitro: A 3D Tumour Model for Pre-therapeutic Drug Screening
}

\author{
DOMINIK NÖRZ ${ }^{1 *}$, CHRISTINA S. MULLINS ${ }^{2 *}$, DANIEL J. SMIT ${ }^{1 *}$, MICHAEL LINNEBACHER $^{2}$, \\ GRITH HAGEL $^{3}$, ALP MIRDOGAN ${ }^{1}$, JACQUELINE SIEKIERA ${ }^{1}$, PATRICK EHM ${ }^{1}$, \\ JAKOB R. IZBICKI ${ }^{4}$, ANDREAS BLOCK ${ }^{5}$, OLE THASTRUP ${ }^{3}$ and MANFRED JÜCKER ${ }^{1}$ \\ ${ }^{1}$ Institute of Biochemistry and Signal Transduction, Center for Experimental Medicine, \\ University Medical Center Hamburg-Eppendorf, Hamburg, Germany; \\ ${ }^{2}$ Molecular Oncology and Immunotherapy, Department of General, Thoracic, \\ Vascular and Transplantation Surgery, University of Rostock, Rostock, Germany; \\ ${ }^{3} 2$ cureX, Birker $\phi$, Denmark; \\ ${ }^{4}$ Department of General, Visceral and Thoracic Surgery, University \\ Medical Center Hamburg-Eppendorf, Hamburg, Germany; \\ ${ }^{5}$ Department of Hematology and Oncology, University Medical Center Hamburg-Eppendorf, Hamburg, Germany
}

\begin{abstract}
Background: Pre-therapeutic analysis of threedimensional spheroid cultures of primary tumour samples is a promising approach of assessing susceptibility to potential treatment. The phosphatidylinositol-3-kinase/AKT serinel threonine kinase/mammalian target of rapamycin (PI3K/ AKT/mTOR) signalling pathway is frequently activated in colorectal cancer (CRC). In previous work, we showed combined inhibition of AKT and mTOR to be highly synergistic in cell lines from patients with hepatocellular carcinoma and cholangiocarcinoma in vitro as well as in vivo in murine xenograft tumour models. Materials and Methods: Patientderived xenograft colorectal carcinoma cell lines HROC80 T1 M1, HROC147 TO M1, HROC147Met, HROC277 TO M1 and HROC277Met2 were treated with AKT inhibitor MK2206, mTOR inhibitor RAD001 or the combination of both drugs. The sensitivity of these cell lines to inhibition was evaluated by
\end{abstract}

This article is freely accessible online.

*These Authors contributed equally as first authors to this work.

Correspondence: Prof. Dr. rer. nat. Manfred Jücker, Institute of Biochemistry and Signal Transduction, Center for Experimental Medicine, University Medical Center Hamburg-Eppendorf, Martinistraße 52, 20246 Hamburg, Germany. Tel: +49 040741056339, Fax: +49 040741052904, e-mail: juecker@uke.de

Key Words: Colorectal cancer, AKT, mTOR, combined treatment, tumour spheroids, tumouroids, pre-therapeutic drug screening, personalized medicine. calculation of combinatory indices after bromodeoxyuridine assays and analysis of the respective pathways by western blotting. Furthermore, the dual inhibition of AKT and mTOR was confirmed in vivo in a xenograft mouse model. Additionally, primary CRC samples of four patients were embedded in a three-dimensional matrix and the sensitivity of these samples was analyzed by measurement of the spheroid area. Results: In this study, we demonstrate that combined treatment with MK2206 and RAD001 resulted in strong synergistic effects on growth of several primary CRC cell lines and reduced the growth of a patient-derived CRC xenograft in a xenotransplantation mouse model in vivo. Interestingly, the response to treatment varied between cell lines derived from the primary lesion and a liver metastasis of the same patient. In addition, combined treatment with AKT and mTOR inhibitors resulted in a synergistic inhibition of tumouroid growth in all four of the primary patient samples, analyzed in a three-dimensional spheroid model in vitro. Conclusion: Our data demonstrate that combined treatment with AKT and mTOR inhibitors exhibits synergistic effects on proliferation of cell lines and primary tumour cells from patients with CRC and may be a promising approach for the treatment of CRC.

Colorectal carcinoma (CRC) is the third most commonly diagnosed type of cancer worldwide, with approximately 1.1 million new cases and more than half a million deaths in 2018 (1). Although mortality rates have recently been on the decline in developed countries, mainly due to extensive screening efforts, CRC still represents one of the most pressing health issues of our time (1). 
Surgical treatment remains the only option that promises to cure the disease. However, many patients with advanced stages of CRC have to be subjected to palliative chemotherapy. CRC arises from normal mucosal epithelium, usually through a series of subsequent mutations, initially leading to a benign adenoma, which will eventually evolve into a colorectal adenocarcinoma over the span of about 10 years (2). About $70 \%$ of CRC cases are due to somatic mutations and 10 to $30 \%$ of cases may involve a familial predisposition (3). Surgery remains the gold standard for treatment of CRC even if patients present with liver metastasis, which occurs in about $25 \%$ of new cases, with another $25 \%$ developing liver metastasis over the course of their treatment (4). More advanced stages of metastatic CRC are subjected to palliative systemic chemotherapy, most commonly with combinations of oxaliplatin, 5-fluorouracil, irinotecan and other agents. Monoclonal antibodies targeting vascular endothelial growth factor (e.g. bevacizumab) or epidermal growth factor receptor (e.g. cetuximab) (5) have also been employed for CRC therapy, provided that the tumour in question exhibits certain genetic features $(6,7)$.

Mutations and aberrant activation are frequently observed in CRC samples in pathways such as the WNT/adenomatous polyposis coli/ $\beta$-catenin pathway, phosphatidylinositol-3kinase/AKT serine/threonine kinase/mammalian target of rapamycin (PI3K/AKT/mTOR) pathway, transforming growth factor beta $\beta /$ small mothers against decapentaplegic, nuclear factor kappa-light-chain-enhancer of activated B cells and mismatch repair genes, among others (3). Given its importance for proliferation, survival and protein synthesis, the PI3K/AKT/mTOR pathway is a promising target in the treatment of cancer (8). In this study, we focused on AKT and its downstream effector mTOR, which exhibit a high rate of overexpression and activation in human CRC (9). Up to one-third of all CRCs harbour an activating mutation in PIK3CA encoding the catalytic subunit of PI3K $(10,11)$. Less frequent mutations are located in regulatory subunits of PI3K (e.g. PIK3R1), in AKT isoforms, mTOR or due to a loss of the negative regulator PI3K, phosphatase and tensin homolog (11).

AKT is a key enzyme in PI3K/AKT/mTOR signalling. Through its downstream effectors it is involved in regulating cell proliferation, survival and migration (12). Detection of high levels of phosphorylated AKT at serine residue 473 has been described in $46 \%$ of CRC samples and was positively associated with proliferation and reduced apoptosis as well as clinicopathologic parameters e.g. venous vessel invasion, clinical stage and lymph node metastasis (13). Additionally, in the early stage of CRC development, overexpression of AKT was reported in up to $60 \%$ of all spontaneous CRC cases (14).

mTOR acts as an integrator for different stimuli including mitogens, energy, and nutrient levels to influence translation, proliferation and autophagy (15). While located downstream of $\mathrm{AKT}$ in the PI3K/AKT/mTOR axis, there are complex interactions and feedback mechanisms in place between these two kinases. AKT controls mTOR activity through the tuberous sclerosis complex $1 / 2$, but in turn requires phosphorylation by mTOR complex 2 for full kinase activity (16). We and others have demonstrated that both the inhibition of mTOR complex 1 (mTORC1), as well as inhibition of both mTOR complexes is not sufficient to effectively diminish AKT activity, as feedback mechanisms restore kinase activity in both cases, providing a rationale for combined vertical targeting of both mTOR and AKT $(17,18)$.

Expression of phosphorylated mTOR and its downstream substrate phosphorylated ribosomal protein S6 kinase beta-1 (P70S6K) were detected in $60.4 \%$ and $65.8 \%$ of CRC tissues samples, respectively, whereas in normal colonic mucosa, detection rates of only $10.0 \%$ and $5.0 \%$ were reported (19). Moreover, high phosphorylation of P70S6K was identified as an independent prognostic marker in CRC and associated with reduced overall survival in multivariate analysis (20). Due to the high frequency of mutations of members, the $\mathrm{PI} 3 \mathrm{~K} / \mathrm{AKT} / \mathrm{mTOR}$ pathway promises to be a valuable target for CRC treatment $(9,21)$.

Targeted therapy is now routinely used for a variety of different cancer types in clinical practice. Upfront or emerging resistance of cancer cells to targeted treatment are ultimately a result of the immense genetic heterogeneity of cells within single lesions, as well as between different tumour sites (22). Identifying, understanding and predicting mechanisms of resistance will be the key to a more effective use of targeted therapy in the future.

One possible approach to predicting tumour behaviour in patients receiving targeted treatment such as kinase inhibitors or inhibitor combinations is the pre-therapeutic testing of their tumour samples in an in vitro environment. This may be achieved in the form of classic cell culture using tumour samples from patients, or in a more realistic threedimensional (3D) model using spheroids (23). The 3D models of cell cultivation promise to mimic hypoxia, dormancy and anti-apoptotic properties of cancer cells (24). Patient-derived spheroid cultures from $\mathrm{CRC}$ which retain individual tumour properties have been successfully established (25). Findings from in vitro studies with corresponding spheroid cultures may be used to select effective treatment regimens for each individual tumour.

Recently, several patient-derived xenograft (PDX) cell lines have been established from primary CRC resection specimens after transplantation in immunocompromised nonobese diabetic severe combined immunodeficiency gamma mice (26). These cell lines, along with many other CRC lines described in literature, can be grouped into five distinct molecular subtypes found in patients with CRC regarding their gene-expression profile, while still exhibiting a high 
degree of diversity in clinical features (27). The PDXderived cell line HROC80 T1 M1 represents the transcriptional profile of the stem cell-like CRC phenotype which originates from transformed stem cells at the bottom of colonic crypts (27). These cells harbour a KRASG12V mutation, but are wild type for $v$-raf murine sarcoma viral oncogene homolog B1 (also referred to as BRAF), PIK3CA and express phosphatase and tensin homolog.

In this study, we investigated the efficacy of combined treatment of primary CRC cell lines with the allosteric AKT inhibitor MK2206 and the mTOR inhibitor RAD001 (everolimus). Cell lines derived from different tumour sites of the same patient were used to observe potential differences in drug efficacy for primary lesions and metastases. Furthermore, 3D spheroid cultures from patients with CRC were analysed for their sensitivity for a combinatorial treatment with AKT and mTOR inhibitors as a proof of concept for pre-therapeutic CRC drug screening.

\section{Materials and Methods}

Reagents. RAD001 was provided by Novartis AG (Basel, Switzerland). MK2206 was obtained from AbMole BioScience (Kowloon, Hongkong); stock solutions at a concentration of $10 \mathrm{mM}$ were prepared and stored at $-80^{\circ} \mathrm{C}$. Resazurin was obtained from Sigma-Aldrich, St Louis, MO, USA.

Patient tumour samples. Tumour samples were collected from four patients (Pt001 to Pt004) with CRC undergoing surgical resection of their tumour either at Bispebjerg Hospital/Rigshospitalet Copenhagen, Denmark or at the University Medical Center Hamburg-Eppendorf. Three patients had their primary colorectal tumour resected whereas one patient with metastatic CRC had liver metastases resected. Collected tumour tissue was placed in cold phosphate-buffered saline (PBS) with antibiotics (500 U/ml penicillin, $500 \mu \mathrm{g} / \mathrm{ml}$ streptomycin, $100 \mu \mathrm{g} / \mathrm{ml}$ gentamicin and $2.5 \mu \mathrm{g} / \mathrm{ml}$ amphotericin B) and transported to the laboratory on ice. The study protocol was approved by the Regional Science Ethics Committee (Ethics Committee of the Rostock University Medical Center, Germany (II HV 43/2004 and A 45/2007); Ethics Committee of the Medical Council Hamburg, Germany (PV4753 and PV5243); and Ethics Committee Region Hovedstaden, Denmark (H-1-2011-125); and written informed consent was obtained from all patients. All experiments involving material of human origin were performed in accordance with relevant guidelines and regulations given by the local authorities and regional Science Ethics Committee.

Tumouroid preparation. Tumouroids were prepared using a modified version of the protocol published by Kondo et al. (28). Tumour tissue was washed in PBS with antibiotics and visible fatty and necrotic areas were carefully removed with a scalpel. The tissue was minced into 1 - to 2 -mm pieces. Tissue was digested with 1 $\mathrm{mg} / \mathrm{ml}$ collagenase type II (Gibco, Thermo Fisher Scientific, Waltham, MA, USA) in PBS with antibiotics for $20 \mathrm{~min}$ at $37^{\circ} \mathrm{C}$. The tissue suspension was aspirated several times with a $1,000 \mathrm{ml}$ pipette prior to filtering sequentially through a $70 \mu \mathrm{m}$ strainer (BD Biosciences, Franklin Lakes, NJ, USA) followed by a $30 \mu \mathrm{m}$ filter
(Miltenyi Biotech, Cologne, Germany). Retained tumour fragments in the $30 \mu \mathrm{m}$ filter were seeded in stem cell medium (StemPro hESC SFM; Thermo Fisher Scientific) supplemented with antibiotics (200 U/ml penicillin, $200 \mu \mathrm{g} / \mathrm{ml}$ streptomycin, $100 \mu \mathrm{g} / \mathrm{ml}$ gentamicin and $2.5 \mu \mathrm{g} / \mathrm{ml}$ amphotericin B) in petri dishes coated with agarose (Sigma-Aldrich) and cultured at $37^{\circ} \mathrm{C}$ in a $5 \% \mathrm{CO}_{2}$ humidified incubator (MCO-19AIC(UV); Panasonic, Hägersten, Sweden). Tissue retained by the $70 \mu \mathrm{m}$ filter was collected and redigested for $5 \mathrm{~min}$ at room temperature and passed through $70 \mu \mathrm{m}$ and $30 \mu \mathrm{m}$ filters as described above. This step was repeated until all tissue passed through the $70 \mu \mathrm{m}$ filter. Tumouroids were allowed to form for 3 to 5 days.

Determination of tumouroid growth inhibition. Tumouroids of four patients with CRC undergoing surgery were prepared as described above. Thereafter, the tumouroid suspension was filtered through a $100 \mu \mathrm{m}$ cell strainer (BD Biosciences, Franklin Lakes, NJ, USA) followed by a $70 \mu \mathrm{m}$ cell strainer to achieve a homogeneous tumouroid preparation free of connective tissue, single cells and debris. A total of 1,500 tumouroids were used for each screening. Tumouroids were added to the 2 cureX IndiTreat ${ }^{\mathrm{TM}}$ screening array (2cureX, Birkerød, Denmark) holding test compounds and controls. Drugs and drug combinations were delivered as drug-eluting beads inside the matrix. The array was incubated in a humidified incubator for 11 days at $37^{\circ} \mathrm{C}$ with $5 \% \mathrm{CO}_{2}$. During the incubation period, images were collected at day $0,4,7$ and 11 using an oCelloscope system (Phillips BioCell, Allerød, Denmark). The obtained images were analysed for changes in spheroid area using proprietary Phillips BioCell and 2cureX algorithms. For each well, the relative growth inhibition was calculated by dividing the total spheroid area by the area of the same well at day 0 and the average of the negative controls on the same day as the day of measurement. Dose-response curves, adjusted $\mathrm{r}^{2}$ values and effective dose 25 values were plotted and calculated using Matlab (MathWorks, Natik, MA, USA).

Cell culture. Cell lines HROC80 T1 M1, HROC147 T0 M1, HROC147Met, HROC277 T0 M1, HROC277Met2 were generated from CRC tumour samples as described previously $(26,29)$. HROC147 T0 M1 and HROC147Met, as well as the HROC277 pair of cell lines were derived from samples of the same patient, from different tumour sites (i.e. primary tumour and liver metastasis). Cells were maintained in Dulbecco's Modified Eagle's medium F12 (Thermo Fisher Scientific), supplemented with $10 \%$ (v/v) fetal calf serum, $2.2 \mathrm{mM} \mathrm{L}$-glutamine and $1 \%(\mathrm{v} / \mathrm{v})$ penicillin and streptomycin. Culture flasks and wells were coated with collagen IV (Sigma-Aldrich) to facilitate attachment and cell growth. Cells were cultured at $37^{\circ} \mathrm{C}$ in a humidified atmosphere containing $5 \% \mathrm{CO}_{2}$.

Cell viability, proliferation and apoptosis assays. Cell viability was analysed by 3-(4,5-dimethylthiazol-2-yl)-2,5-diphenyl-2H-tetrazolium bromide (also referred to as MTT) or Alamar blue viability assay, as described elsewhere (30). Briefly, cells were seeded into 96-well plates and allowed to adhere overnight, followed by treatment with AKT inhibitor MK2206 (21 to 5,000 nM), mTOR inhibitor RAD001 (4 to $1,000 \mathrm{nM})$, the combination of MK2206/RAD001 (21 nM/4 nM to $5,000 \mathrm{nM} / 1,000 \mathrm{nM}$ ) or DMSO as control. After $72 \mathrm{~h}, 100 \mu \mathrm{l}$ cell culture medium containing $5 \mathrm{ng} / \mathrm{ml}$ resazurin was added to each well, and cells were incubated for 1 to $3 \mathrm{~h}$ at $37^{\circ} \mathrm{C}$ in a humidified atmosphere. Fluorescence based absorption was measured at $540 \mathrm{~nm}$ on a micro plate reader (Tecan, Switzerland). 
Proliferation was analysed by BrdU enzyme-linked immunoassay (ELISA). Cells were seeded into 96-well plates and allowed to attach overnight. Cells were then incubated for $72 \mathrm{~h}$ with the AKT inhibitor MK2206 (21 to 5,000 nM), mTOR inhibitor RAD001 (4 nM to $1,000 \mathrm{nM}$ ) or the combination of MK2206/RAD001 (21 nM/4 nM to $5,000 \mathrm{nM} / 1,000 \mathrm{nM}$ ), and controls were treated with DMSO only. BrdU ELISA assays were performed as described by the manufacturer (Roche, Basel, Switzerland). Incubation time with BrdU was adjusted to account for slow proliferation of cells but did not exceed recommended incubation times provided by Roche.

Apoptosis was analysed by western blot analysis with antibodies directed against poly-adenosine diphosphate-ribose polymerase 1 (PARP1) as described in the western blot analysis section. Cells were seeded in $10 \mathrm{~cm}$ plates for $24 \mathrm{~h}$ and then treated with the inhibitors MK2206 (5,000 nM), RAD001 $(1,000 \mathrm{nM})$ or a combination of MK2206 (5,000 nM) and RAD001 (1,000 nM). As a negative control, cells were treated with DMSO. Apoptosis was induced by treatment of cells with staurosporine $(2,000 \mathrm{nM})$ for 6 $\mathrm{h}$ and $24 \mathrm{~h}$. Before lysing the cells, the inhibitors were added to the cells again for $1 \mathrm{~h}$. Then the cell culture media was aspirated, and the cells were washed with $10 \mathrm{ml}$ PBS. Cell extracts were prepared by addition of $600 \mu \mathrm{l}$ NP40 lysis buffer. After centrifugation at $10,000 \times g$ at $4^{\circ} \mathrm{C}$ for $10 \mathrm{~min}$, the supernatant was collected and stored at $-80^{\circ} \mathrm{C}$ until protein determinations were carried out.

Western blot analysis. Western blot analysis was performed as described previously (31). Protein concentration in cellular extracts was determined using the BioRad DC protein assay. Thirty micrograms of each sample was then separated by electrophoresis on a $10 \%$ sodium dodecyl sulfate polyacrylamide gel in a trisglycine running buffer and blotted on a nitrocellulose blotting membrane (GE Healthcare). For the detection of the proteins, the membrane was blocked for $1 \mathrm{~h}$ with tris-buffered saline (TBS) containing $0.5 \%$ Tween with $5 \%$ non-fat dried milk powder at room temperature. The membrane was then incubated with primary antibodies in TBS containing $0.5 \%$ Tween and $2.5 \%$ non-fat dried milk powder overnight at $4^{\circ} \mathrm{C}$. The antibodies directed against, phospho-AKT (S473) (D9E) [\#4060], phospho-AKT (T308), phospho-mTOR (S2448) [\#2971], phospho-S6 ribosomal protein (S235/S236), phospho-mitogen-activated protein kinase kinase (MEK) (S217/221), phospho-extracellular-signal regulated kinase (ERK) (T202/Y204), cyclin-dependent kinase inhibitor 1B (p27KIP1) and PARP were purchased from Cell Signaling Technology (Beverly, MA, USA), and antibodies against HSC70 (B6) were purchased from Santa Cruz Biotechnology (Heidelberg, Germany). Primary antibodies were used at a dilution of 1:1,000. After incubation overnight and washing steps, the secondary antibody coupled to horseradish peroxidase was added at a dilution of $1: 5,000$ to the membranes for $1 \mathrm{~h}$ at room temperature. Thereafter, the membrane was incubated with luminol reagents (Super Signal West Pico Plus; Thermo Scientific) and chemiluminescence signals were detected and quantified using LAS-3000 Imager from Fuji (Raytest, Straubenhardt, Germany).

Tumour spheroid experiments. A total of $2 \times 10^{4}$ HROC80 T1 M1 cells were plated in an ultra-low attachment plate (Corning, NY, USA) and centrifuged at $145 \times g$ for $5 \mathrm{~min}$. Tumouroid formation of HROC80 T1 M1 cells was monitored using an IncuCyte ZOOM ${ }^{\circledR}$ live-cell imaging system (Essen BioScience, Ann Arbor, MI, USA) for $120 \mathrm{~h}$ at $37^{\circ} \mathrm{C}$ and with $5 \% \mathrm{CO}_{2}$. Afterwards, MK2206, RAD001 or MK2206-RAD001 were added to the wells at final concentrations of $1,000 \mathrm{nM}, 100 \mathrm{nM}$ and $1,000 \mathrm{nM} / 100 \mathrm{nM}$, respectively and the plate was scanned for 7 additional days. To determine the tumouroid area, a cell confluency mask was adjusted for the HROC80 T1 M1 tumouroids and the surrounding cells. The area of the tumouroids was quantified using IncuCyte ZOOM software. Statistical analysis of the data was carried out in GraphPad Prism 6 (GraphPad Software Inc., San Diego, CA, USA).

Tumour xenograft model and in vivo drug treatment. All animal experimental procedures were approved by the National Animal Welfare Committee (Landesamt für Landwirtschaft, Lebensmittelsicherheit und Fischerei Mecklenburg-Vorpommern) (permit numbers: LALLF M-V/TSD/7221.3-1.1-098/12) and performed according to institutional guidelines of animal husbandry and welfare.

Cubes of $3 \times 3 \times 3 \mathrm{~mm}$ PDX HROC80 tissue were implanted into the left flank of NMRI-Foxn1nu/nu mice (in-house breeding, NMRI-Foxn1nu) $(n=15)$. The mice were randomized into two groups and group sizes were determined empirically. MK2206 and RAD001 were prepared as described previously (32). Briefly, MK2206 was prepared in a 30\% Captisol $^{\circledR}$ solution. RAD001 was prepared as a microemulsion (provided by Novartis AG). A placebo microemulsion (provided by Novartis AG) and a $30 \%$ Captisol $^{\circledR}$ solution served as placebo for the control group. Treatment with MK2206 and RAD001 (100 mg/kg MK2206 with $5 \mathrm{mg} / \mathrm{kg}$ RAD001; $n=8$ ) or Captisol ${ }^{\circledR}$ and vehicle (control, $n=7$ ) was applied orally by gavage for 25 days. Tumour size was measured using a calliper square. No general toxicity due to the inhibitor treatment was observed in the treatment group. Animals were euthanized using carbon dioxide followed by cervical dislocation at the end of the study and tumours were carefully excised, weighed and prepared for further analysis. No inclusion and exclusion criteria were set. No mice were lost during this study and no data points were excluded. In order to minimise potential confounders, the order of treatments and measurements was randomized at each time point and animals were distributed equally in cages. Only people administering the treatment were aware of group allocation.

Statistical analysis. Data analysis was performed with GraphPad Prism 8. Results were considered statistically significant if $p<0.05$.

Calculation of combination indices. CompuSyn software (ComboSyn, Inc., Paramus, NJ, USA) was used to calculate the combination index (CI) according to the Chou and Talalay method (33) for each combination point. CI values from 0.3 to 0.7 are considered to indicate synergism, CI values below 0.3 are considered to represent strong synergism, and values below 0.1 very strong synergism. The CI values were used to draw a plot of CI values over a range of fractions affected as described elsewhere (33).

\section{Results}

Combined inhibition of AKT and mTORC1 is highly efficacious and synergistic in primary CRC cell lines in vitro. We first analysed whether HROC80 T1 M1 cells are affected by treatment with AKT and mTOR inhibitors. Proliferation of HROC80 T1 M1 cells was strongly affected in a dosedependent manner by treatment with the allosteric pan-AKT 
inhibitor MK2206 and in a dose-independent manner by the mTOR inhibitor RAD001. Simultaneous inhibition of AKT/mTORC1 resulted in a complete inhibition of proliferation at the highest concentrations (Figure 1A and B) as well as strong synergistic effects, with CIs well below 0.3 along the entire dose gradient (Table I). Drug effects on cellular signalling were confirmed by western blot analysis (Figure 1C), demonstrating thorough suppression of phosphorylation of AKT (serine residue 473 and threonine residue 308) after MK2206 treatment and of ribosomal protein S6 (pS6 S235/236) when RAD001 was administered. Ribosomal protein $\mathrm{S} 6$ is a substrate of p70S6K, which is an important downstream target of mTORC1 and was therefore used as an indicator of the level of mTORC1 activity. Treatment of cells with RAD001 also resulted in increased phosphorylation of AKT at threonine residue 308 in HROC80 T1 M1 and all other tested cell lines (Figure 1C) as part of a feedback mechanism that has been described in detail in previous work $(34,35)$. The abundance of the cell-cycle inhibitor p27KIP1, which is a downstream target of AKT, was increased after inhibition of AKT, and further increased after combinatorial treatment, corresponding well with the complete inhibition of proliferation, as described above. Further analysis of the RAS/RAF/MEK/MAPK pathway revealed an increased phosphorylation of MEK (S217/221) after inhibition of AKT but not after inhibition of mTOR.

The PI3K/AKT/mTOR pathway can effectively inhibit apoptosis due to AKT-dependent phosphorylation of several substrates including BCL2-associated antagonist of cell death, caspase- 9 and others. However, inhibition of AKT and mTOR in HROC80 T1 M1 cells, whether alone or in combination, did not induce a significant increase in apoptosis as analysed by cleaved PARP protein, whereas treatment with staurosporine resulted in strong induction of apoptosis (Figure 1D and E).

Combined targeting of AKT and mTOR reduced CRC tumouroid formation in vitro and tumour growth in vivo. We further analysed the combinatorial effect of AKT and mTOR inhibitors on CRC tumouroid formation. HROC80 T1 M1 cells formed multiple heterogeneous tumouroids in an ultralow attachment plate (Figure 2A). Growth of tumouroids treated with MK2206 and RAD001, both alone and in combination, was significantly reduced (Figure $2 \mathrm{~B}$ and $\mathrm{C}$ ). Compared to the control, tumouroids treated with MK2206, RAD001 and their combination exhibited area increases of only $19.7 \%, 21.7 \%$ and $8.3 \%$, respectively, after 7 days of treatment (Figure $2 \mathrm{~B}$ and $\mathrm{C}$ ). To confirm the reliability of automated confluence measurements, single tumouroids were also measured manually to confirm the significant inhibition of tumouroid growth by AKT and mTOR inhibition (Figure $2 \mathrm{D}$ and $\mathrm{E})$. Although the size of the tumouroids was significantly reduced by AKT and mTOR inhibitors, the total
Table I. Tabular view of the total doses of AKT serine/threonine kinase (AKT) inhibitor MK2206 and mammalian target of rapamycin (mTOR) inhibitor RAD001 used, the fractional effect on proliferation, and the resulting combination index (CI) according to the Chou and Talalay method for patient-derived xenograft colorectal cancer cell lines HROC8O T1 M1, HROC147 TO M1, HROC147Met and HROC277 TO M1. CI values were determined using CompuSyn software (ComboSyn Inc., Paramus, NJ, USA).

\begin{tabular}{|c|c|c|c|}
\hline & $\begin{array}{c}\text { Total dose of } \\
\text { MK2206/ } \\
\text { RAD001, nM }\end{array}$ & $\begin{array}{c}\text { Fractional } \\
\text { effect }\end{array}$ & $\begin{array}{c}\text { Combinatior } \\
\text { index }\end{array}$ \\
\hline \multirow{6}{*}{ HROC80 T1 M1 } & $21 / 4$ & 0.36 & 0.21 \\
\hline & $62 / 12$ & 0.42 & 0.08 \\
\hline & $185 / 37$ & 0.69 & 0.11 \\
\hline & $556 / 111$ & 0.87 & 0.18 \\
\hline & $1,667 / 333$ & 0.98 & 0.17 \\
\hline & $5,000 / 1,000$ & 1 & 0.08 \\
\hline \multirow[t]{6}{*}{ HROC147 T0 M1 } & $21 / 4$ & 0.05 & 8.41 \\
\hline & $62 / 12$ & 0.10 & 0.89 \\
\hline & $185 / 37$ & 0.12 & 1.06 \\
\hline & $556 / 111$ & 0.15 & 1.16 \\
\hline & $1,667 / 333$ & 0.27 & 0.28 \\
\hline & $5,000 / 1,000$ & 0.44 & 0.30 \\
\hline \multirow[t]{6}{*}{ HROC147Met } & $21 / 4$ & 0.13 & 0.01 \\
\hline & $62 / 12$ & 0.14 & 0.03 \\
\hline & $185 / 37$ & 0.26 & 0.03 \\
\hline & $556 / 111$ & 0.38 & 0.07 \\
\hline & $1,667 / 333$ & 0.61 & 0.12 \\
\hline & $5,000 / 1,000$ & 0.74 & 0.25 \\
\hline \multirow[t]{6}{*}{ HROC277 T0 M1 } & $21 / 4$ & 0.08 & 0.43 \\
\hline & $62 / 12$ & 0.17 & 0.45 \\
\hline & $185 / 37$ & 0.22 & 0.95 \\
\hline & $556 / 111$ & 0.44 & 1.00 \\
\hline & $1,667 / 333$ & 0.68 & 1.09 \\
\hline & $5,000 / 1,000$ & 0.91 & 0.68 \\
\hline \multirow[t]{6}{*}{ HROC277Met2 } & $21 / 4$ & 0.00 & 1.11 \\
\hline & $62 / 12$ & 0.00 & 3.27 \\
\hline & $185 / 37$ & 0.31 & 0.25 \\
\hline & $556 / 111$ & 0.55 & 0.50 \\
\hline & $1,667 / 333$ & 0.77 & 1.00 \\
\hline & $5,000 / 1,000$ & 0.94 & 1.57 \\
\hline
\end{tabular}

number of tumouroids was not reduced by inhibitor treatment (data not shown).

The tumour formation capacity was further analysed in a PDX mouse model of HROC80 T1 M1 cells in vivo. Despite the strong effects on proliferation in 2D cell culture experiments and tumouroid growth as shown in Figure 1 and 2, respectively, combined treatment with MK2206 and RAD001 resulted only in a small but significant effect on tumour size after 25 days ( $p=0.0161$ ) (Figure 3A). However, there was no significant effect on overall survival of the treated mice (data not shown).

Analysis of the PDX tumours revealed that treatment with MK2206 and RAD001 did not markedly reduce the 
A

HROC80 T1 M1

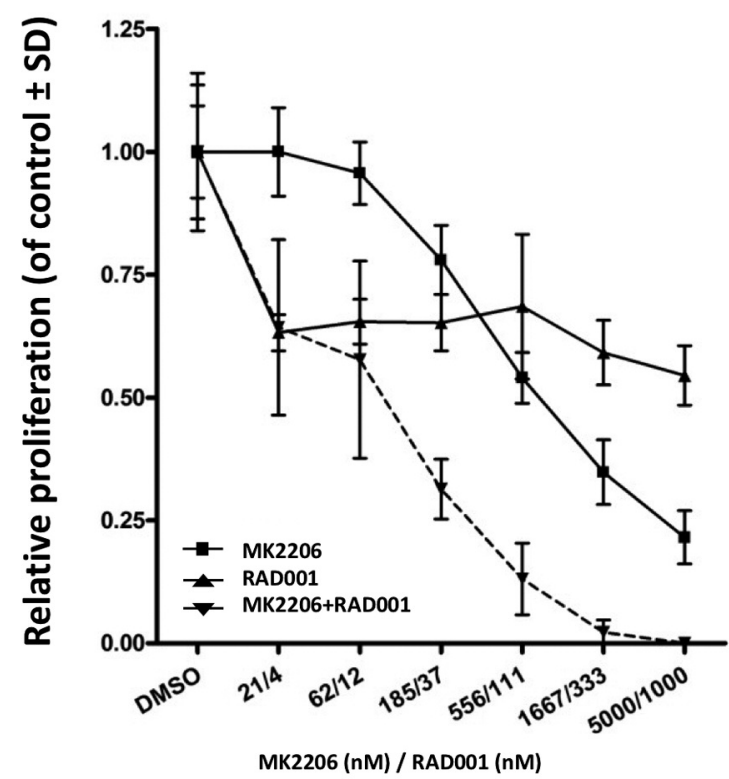

B $\quad$ HROC80 T1 M1

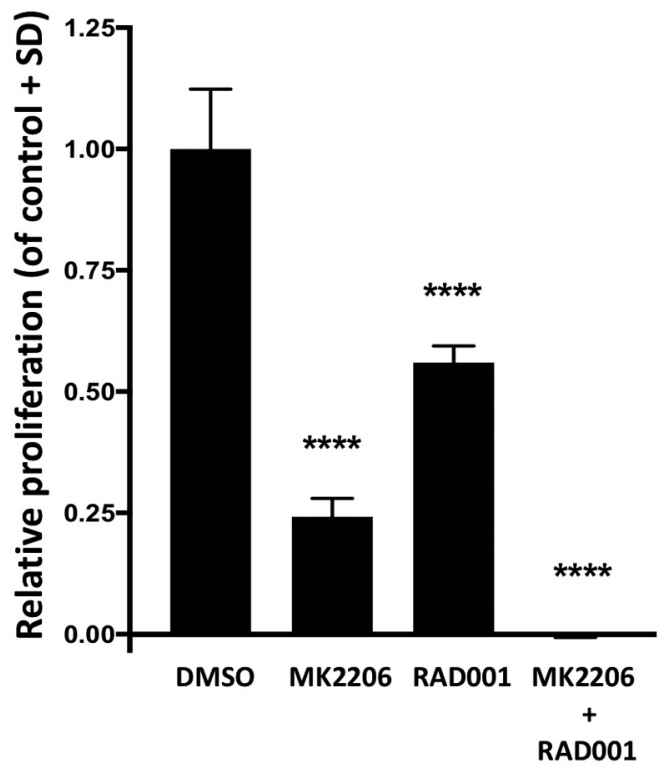

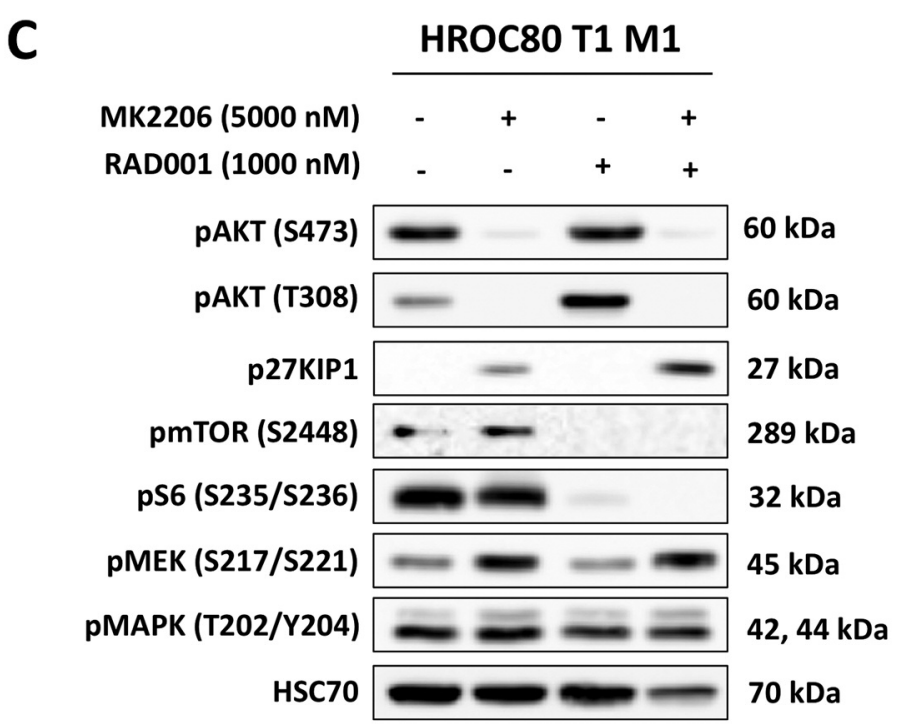

Figure 1. Continued

expression of phosphorylated AKT (S473) and phosphorylated S6 (S235/S236) compared to the control (Figure 3B). Densitometric analysis revealed a similar expression of phosphorylated AKT at serine residue 473 $(p=0.95)$ and a slightly but not significantly lower expression of phosphorylated S6 (S235/S236) $(p=0.59)$ in treated mice (Figure 3C). This may indicate a complete resistance of HROC80 T1 M1 PDX to AKT inhibition using MK2206 while partly retaining susceptibility to the mTOR inhibitor RAD001. The expression of pMEK (S217/S221), pMAPK (T202/Y204) and p27KIP1 did not significantly differ between the treatment and control groups (Figure 3B).

Cell lines derived from primary tumour and metastases of the same patient responded differently to combined treatment. HROC147 T0 M1 and HROC147Met cell lines 
D HROC80 T1 M1

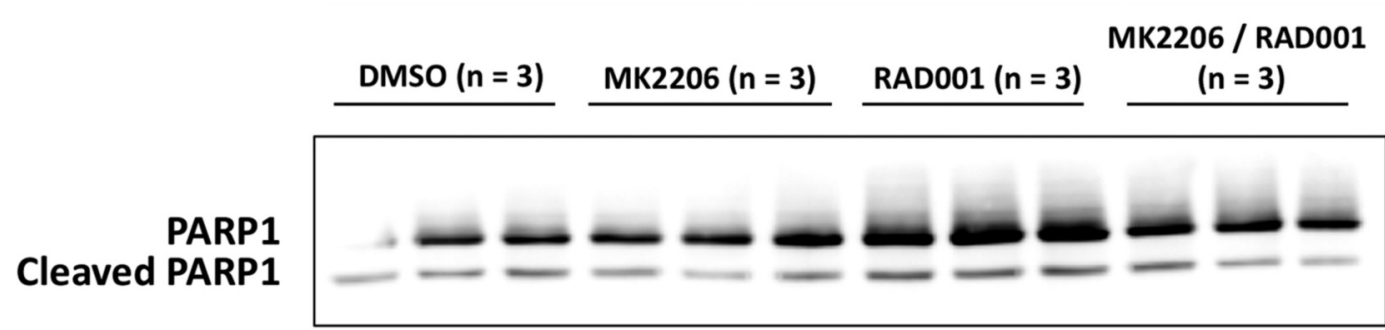

116 kDa 89 kDa

HSC70

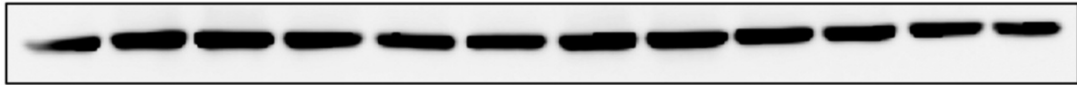

70 kDa

HROC80 T1 M1

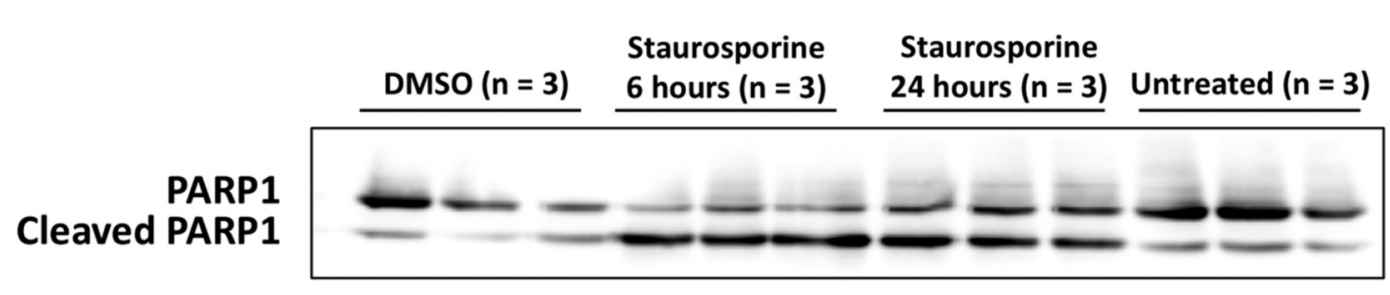

$116 \mathrm{kDa}$ $89 \mathrm{kDa}$

HSC70

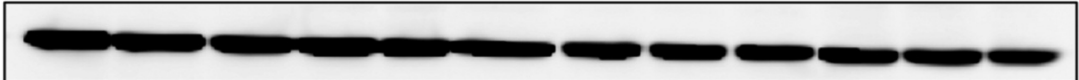

70 kDa

\section{E}

HROC80 T1 M1

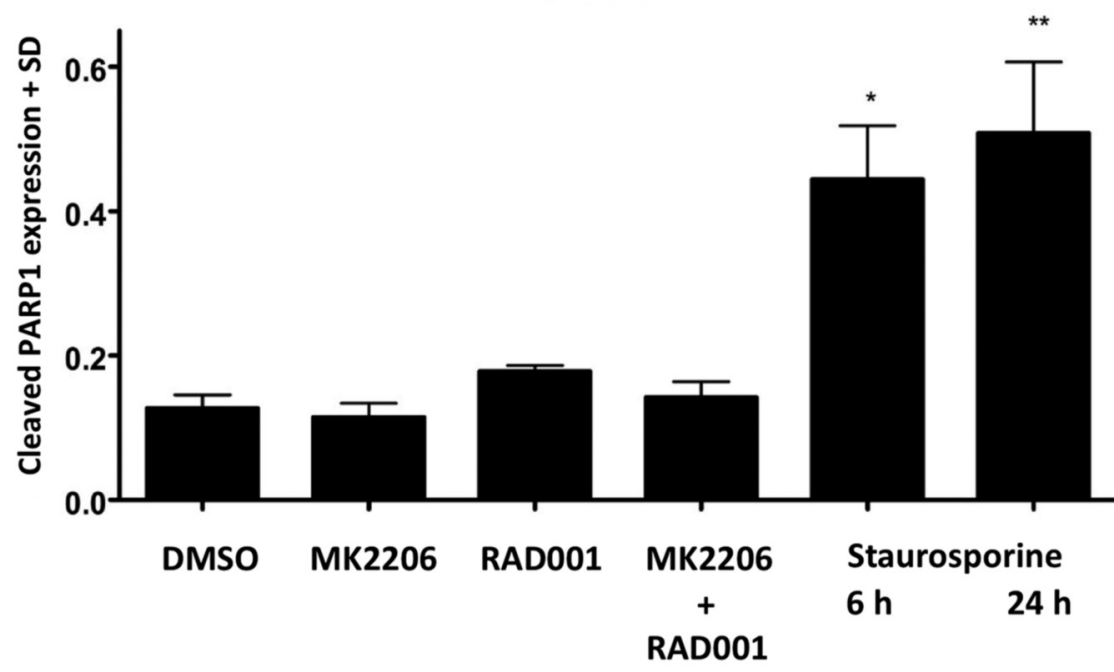

Figure 1. Synergistic effects on proliferation of colorectal carcinoma cell line HROC80 T1 M1 after combined treatment with AKT serinelthreonine kinase (AKT) and mammalian target of rapamycin (mTOR) inhibitors. A: HROC80 T1 M1 cells were cultured for $72 \mathrm{~h}$ in the presence of increasing concentrations of AKT inhibitor MK2206 or mTOR inhibitor RAD001 alone and in combination in a fixed ratio (5:1 MK2206/RAD001). BrdU enzymelinked immunoassays were then performed. The exact combination index values and fractional effects are listed in Table I. B: The effect of MK2206 $(5,000 \mathrm{nM})$ and RAD001 (1,000 nM), alone and in combination (5,000 nM/1,000 nM), on proliferation of HROC80 T1 M1 cells. C: Changes in AKT, mTOR and MAPK signalling pathway activity in HROC80 T1 M1 cells were analysed by western blot after treatment for $24 \mathrm{~h}$ with 5,000 nM MK2206 and 1,000 nM RAD001, alone and in combination. Housekeeping protein heat-shock cognate $71 \mathrm{kDa}$ protein (HSC70) was used as a loading control. Data are the mean \pm SD. D: Western blot analysis of HROC80 T1 M1 cells treated with AKT and mTOR inhibitors (5,000 nM MK2206, 1,000 nM RAD001) alone and in combination, using specific primary antibodies against poly adenosine diphosphate ribose polymerase 1 (PARP1) (cleaved and uncleaved). E: Densitometric quantification of the western blot analysis shown in D. HROC80 T1 M1 cells incubated with staurosporine (2,000 nM) for 6 and $24 h$ were used as a positive control. Significantly different from the control at $* p<0.05$, $* * p<0.01$ and $* * * * p<0.0001$ by one-way ANOVA with Dunnett's multiple comparisons test. DMSO: Dimethyl sulfoxide; p27KIP1: cyclin-dependent kinase inhibitor 1B; pMEK: phosphorylated mitogenactivated protein kinase kinase; pMAPK: phosphorylated mitogen-activated protein kinase; pS6: phosphorylated S6 protein. 

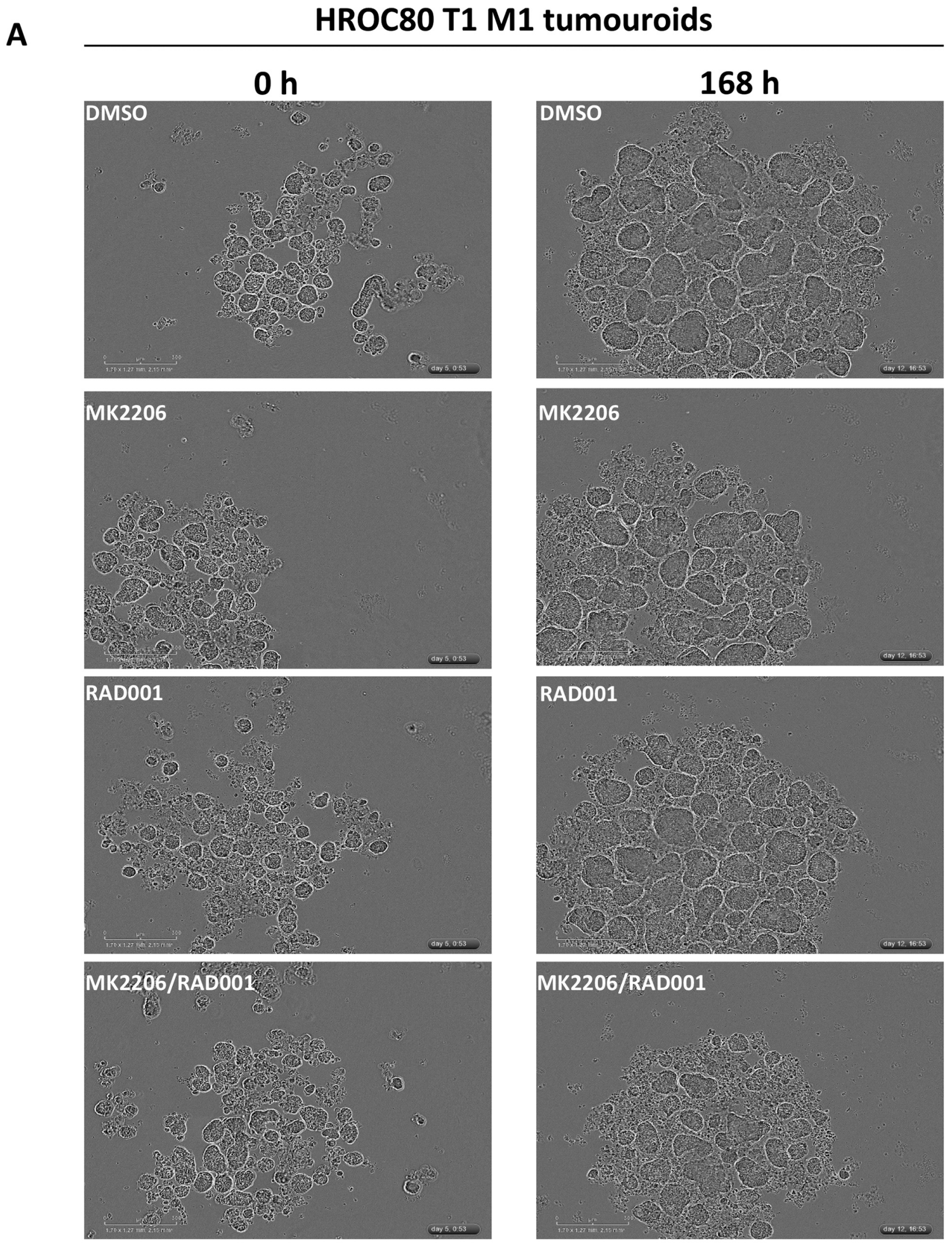

Figure 2. Continued 

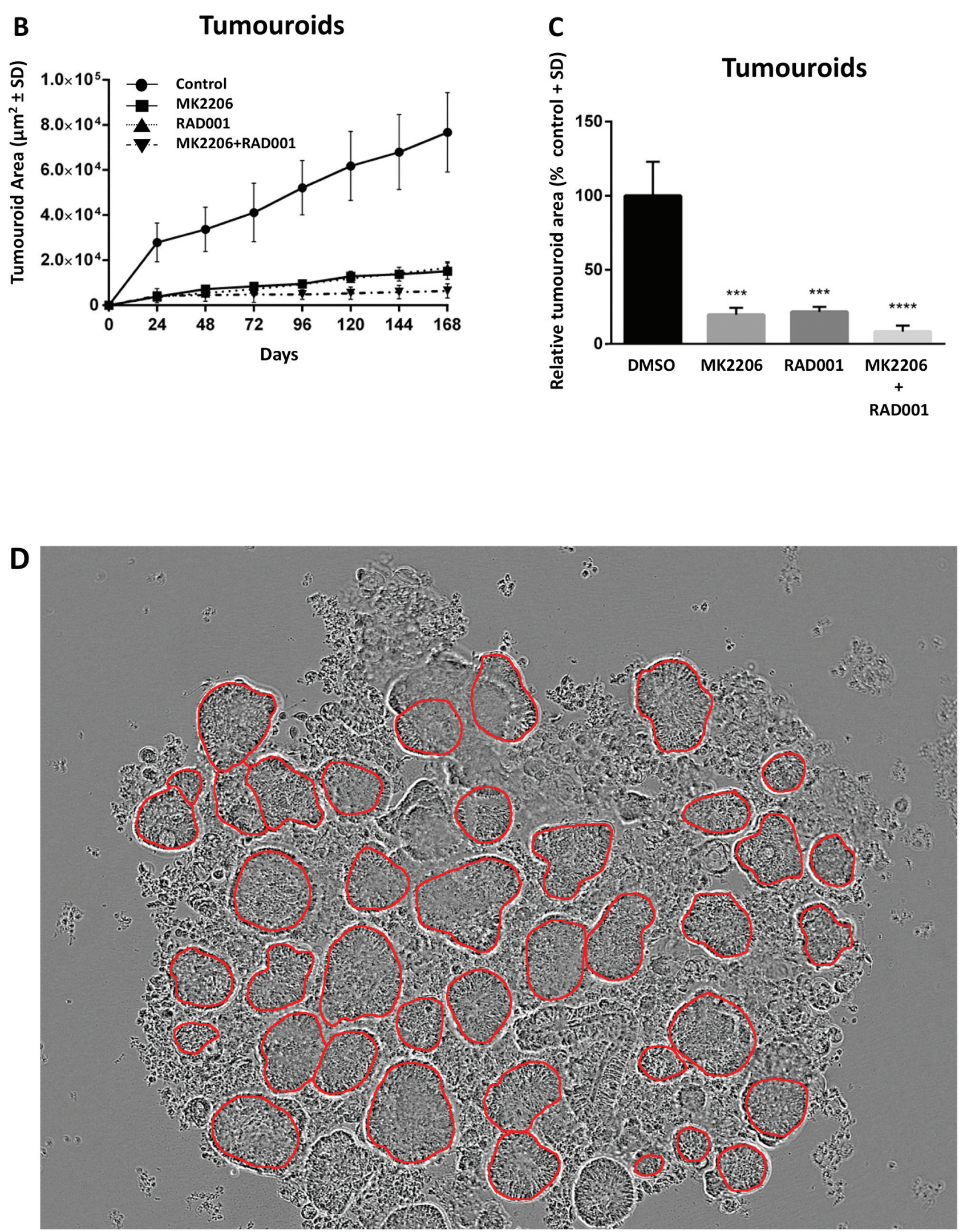

Figure 2. Continued 


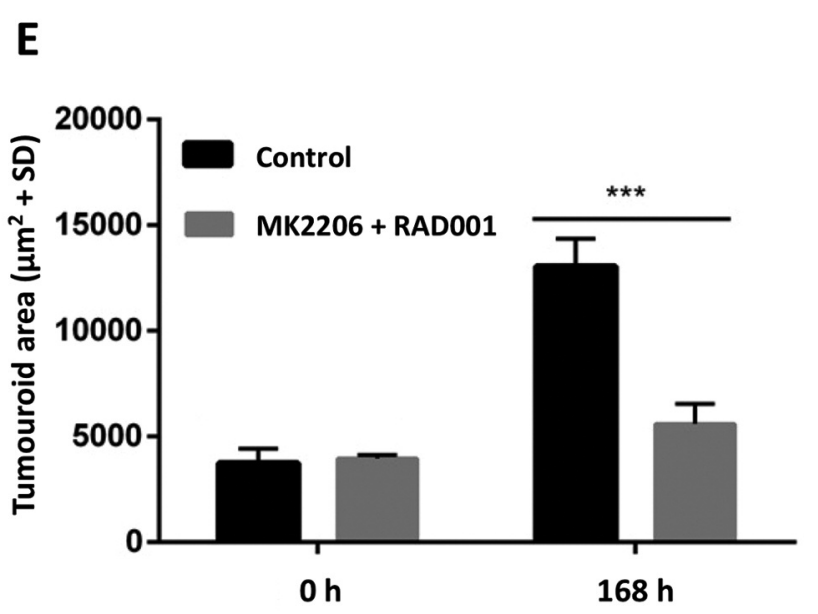

Figure 2. A: HROC80 T1 M1 tumouroid formation in an ultra-low attachment plate after seeding and after $168 \mathrm{~h}$ of treatment with AKT serine/threonine kinase (AKT)/mammalian target of rapamycin (mTOR) inhibitors MK2206 (5000 nM)/RAD001 (1000 nM), alone and in combination. Representative scans of HROC80 T1 M1 cells forming heterogenous tumouroids with surrounding cells. The scans were acquired using the IncuCyte Zoom system (Essen Biosciences, Ann Arbor, MI, USA) at 10-fold magnification. B: HROC80 T1 M1 cells were plated in ultra-low attachment plates and incubated for 5 days to form tumouroids. Thereafter, tumouroids were treated with vehicle dimethyl sulfoxide (DMSO) as a control, AKT inhibitor MK2206 (1,000 nM), mTOR inhibitor RAD001 (100 nM) or with the combination of both inhibitors. The tumouroid area was measured every day for 7 days. $C$ : Relative increase of growth of HROC80 T1 M1 tumouroids after treatment as shown in B with AKT and mTOR inhibitors compared to those treated with DMSO. Statistical analysis was performed by oneway ANOVA with Dunnett's multiple comparisons test; significantly different from the control at: $* * * p<0.001$ and $* * * * p<0.0001 . D$ : Representative image for the validation of the automated confluence determination by manual measurement of fully formed HROC80 T1 M1 tumouroids. E: Manually measured tumouroid area of HROC80 T1 M1 tumouroids shown in A treated with the combination of AKT inhibitor MK2206 (1,000 $n M)$ and mTOR inhibitor RAD001 (100 nM). ***Significantly different at $p<0.001$ by unpaired, two-sided $t$-test. Data are the mean \pm standard deviation $(S D)$.

were derived from samples of the primary tumour and a liver metastasis, respectively, from the same patient. HROC147 T0 M1 cells proved to be relatively resistant to combined treatment, with only about $25 \%$ less BrdU incorporation, compared to controls at a concentration of $5,000 \mathrm{nM}$ and 1,000 nM of MK2206 and RAD001, respectively (Figure $4 \mathrm{~A}$ ), and only weak synergistic effects (Table I). HROC147Met, however, proved to be fairly sensitive to combined treatment, showing an approximately 50\% reduction in BrdU incorporation at a concentration of 5,000 $\mathrm{nM}$ and 1,000 nM of MK2206 and RAD001, respectively (Figure 4B), and CI values below 0.3 along the entire dose gradient (Table I), indicating strong synergistic effects.
In contrast, HROC277 T0 M1 (Figure 4C) and HROC277Met 2 (Figure 4D), also derived from different tumour sites within the same patient, both exhibited high susceptibility to combined treatment, without significant differences between them (Figure 4C and D) (Table I).

Western blot analysis was carried out for phosphorylated MEK and ERK, as there is some functional overlap and extensive crosstalk between the RAS/RAF/MEK/ERK and $\mathrm{PI} 3 \mathrm{~K} / \mathrm{AKT} / \mathrm{mTOR}$ pathways, with the potential to compensate for loss of activation in either one of them. Treatment with MK2206 led to higher levels of phosphorylated MEK in all cell lines analysed (Figures 1C, 4E and 4F). Liver metastasis HROC147Met in particular exhibited a distinct increase of phosphorylated MEK expression under combined treatment (Figure 4E). However, the only cell line to show a substantial up-regulation of phosphorylated ERK was the primary tumour cell line HROC277 T0 M1 when treated with both inhibitors (Figure 4F).

Reduced tumouroid formation by CRC patient-derived tumour cells after AKT and mTOR inhibition. Primary CRC samples were obtained from four patients undergoing surgery, processed and embedded in a 3D matrix (Figure 5A). Single treatment with AKT or mTOR inhibitors reduced tumouroid growth, which was further reduced by combined targeting of AKT/mTOR (Figure 5B). Dose-dependent effects on tumouroid growth were observed with the AKT inhibitor, whereas the effects of RAD001 were largely independent of dosage. In all four cases analysed, combined treatment with AKT and mTOR inhibitors further reduced growth of primary CRC tumouroids (Figure 5B). Dual AKT and mTOR inhibition using MK2206 and RAD001 exhibited consistently synergistic to strong synergistic effects with CI values below 0.4 along the entire dose gradient in tumour samples from Pt001 (Table II). In the other tested samples (i.e. Pt002, Pt003 and Pt004) the combinatory treatment with MK2206 and RAD001 featured synergistic effects of varying degrees, with all showing strong synergistic effects and CI values below 0.3 along parts of the dose gradient (Table II). Combined treatment with MK2206 and RAD001 (5,000 nM/1,000 nM) proved to be significantly superior to the effects of single drugs in three out of four samples tested, namely Pt001, Pt002 and Pt004 (Figure 5C). In Pt002, combined treatment with MK2206 and RAD001 was able to enhance the inhibitory effect compared to single RAD001 treatment, while the inhibitory effect of upstream AKT inhibition with MK2206 was not further enhanced by dual targeting of AKT and mTOR (Figure 5C).

\section{Discussion}

In this work, we aimed to provide evidence for the efficacy of combined treatment of CRC with AKT and mTOR 
A

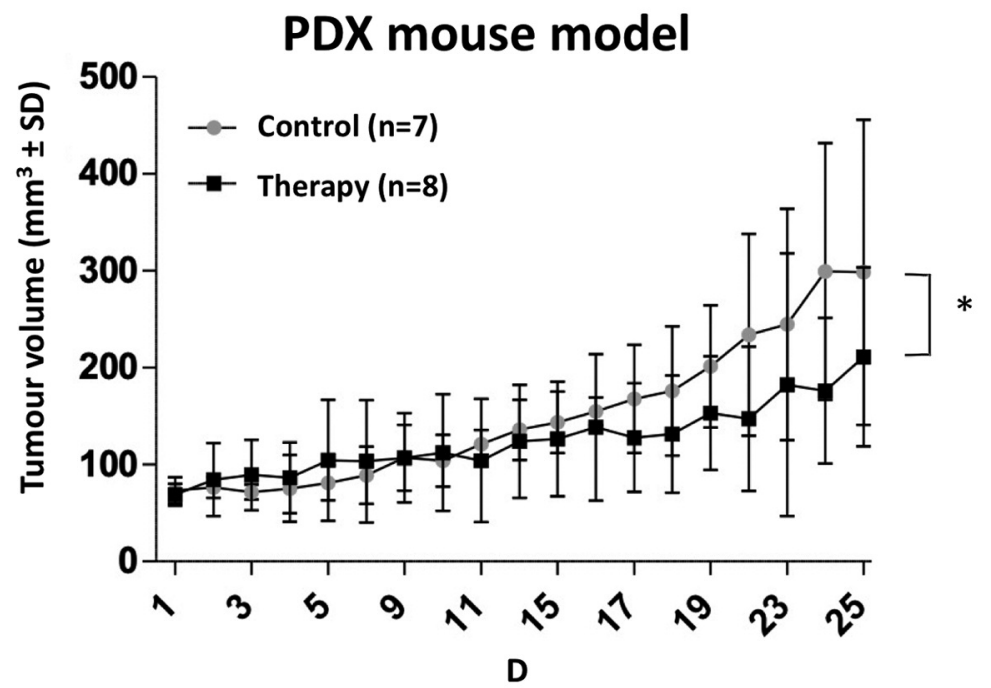

B

Control

Treatment

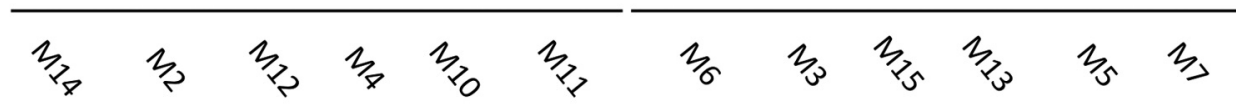

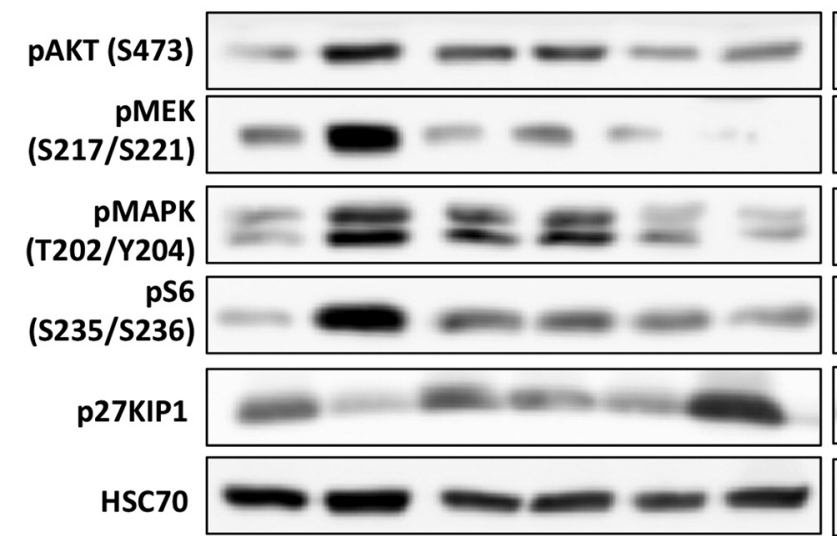

C

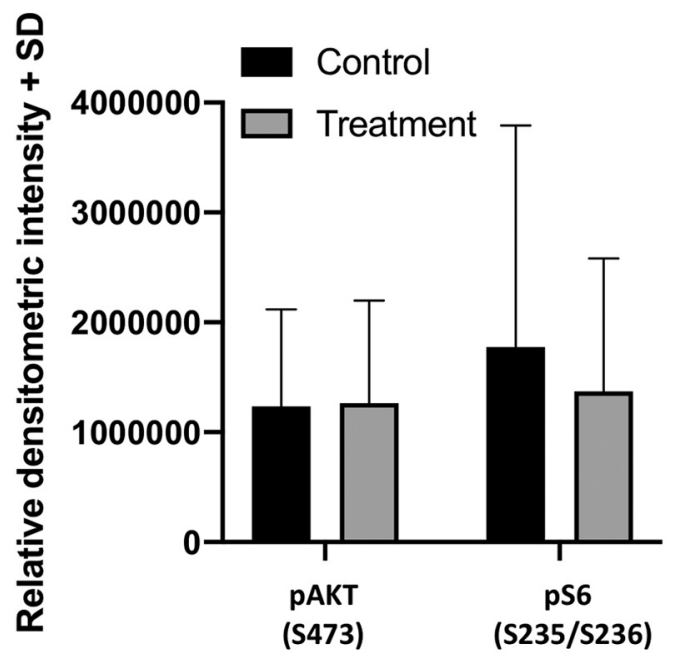

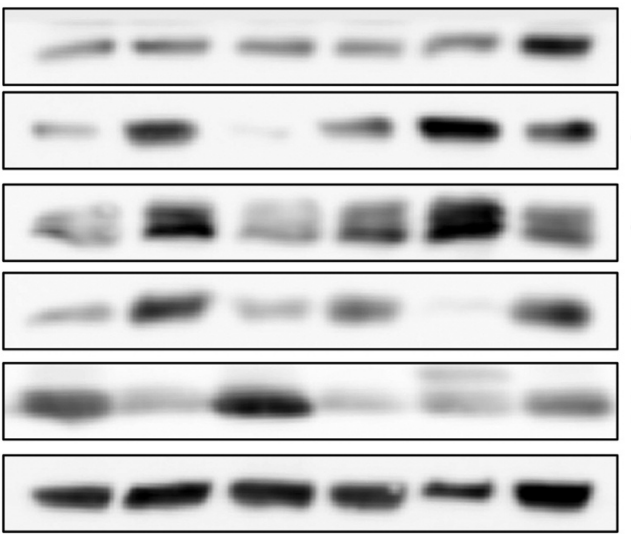

$60 \mathrm{kDa}$

$45 \mathrm{kDa}$

$42,44 \mathrm{kDa}$

$32 \mathrm{kDa}$

$27 \mathrm{kDa}$

$70 \mathrm{kDa}$

Figure 3. A: Cubes of $3 \times 3 \times 3 \mathrm{~mm}$ of HROC80 patient-derived xenografts $(P D X)$ were implanted subcutaneously in NMRI nu/nu mice and tumour growth was measured at the indicated times. An unpaired two-sided $t$ test was used to determine the difference between the groups. The control group was treated with Captisol@ and vehicle $(n=7)$ and therapy group $(n=8)$ was treated with the combination of AKT serine/threonine kinase (AKT) inhibitor MK2206 (100 $\mathrm{mg} / \mathrm{kg})$ and mammalian target of rapamycin (mTOR) inhibitor RAD001 (5 mg/kg) by gavage for 25 days. B: Western blot analysis of cellular signalling proteins in HROC80 T1 M1 PDX mouse tumours after careful excision. Housekeeping protein heat-shock cognate $71 \mathrm{kDa}$ protein (HSC70) was used as a loading control. C: Densitometric analysis of the western blots from HROC80 T1 M1 PDX as shown in B $(n=6)$. Statistical analysis was performed using an unpaired, two-sided t-test. Densitometric readings of phosphorylated AKT (pAKT) (S473) and pS6 (S235/S236) were normalized to that of housekeeping protein HSC70 prior to analysis. Data are the mean \pm standard deviation $(S D)$. *Significantly different from the control at $p<0.05$. p27KIP1: cyclin-dependent kinase inhibitor $1 B$; pmTOR: phosphorylated mTOR; pS6: phosphorylated S6; pMEK: phosphorylated mitogen-activated protein kinase kinase; pMAPK: phosphorylated mitogen-activated protein kinase. 
A

HROC147 TO M1

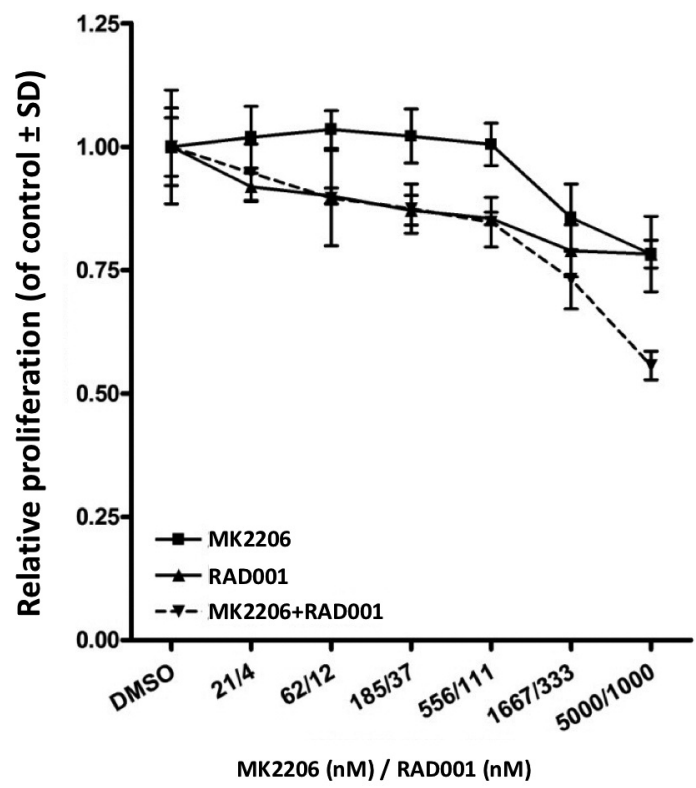

C

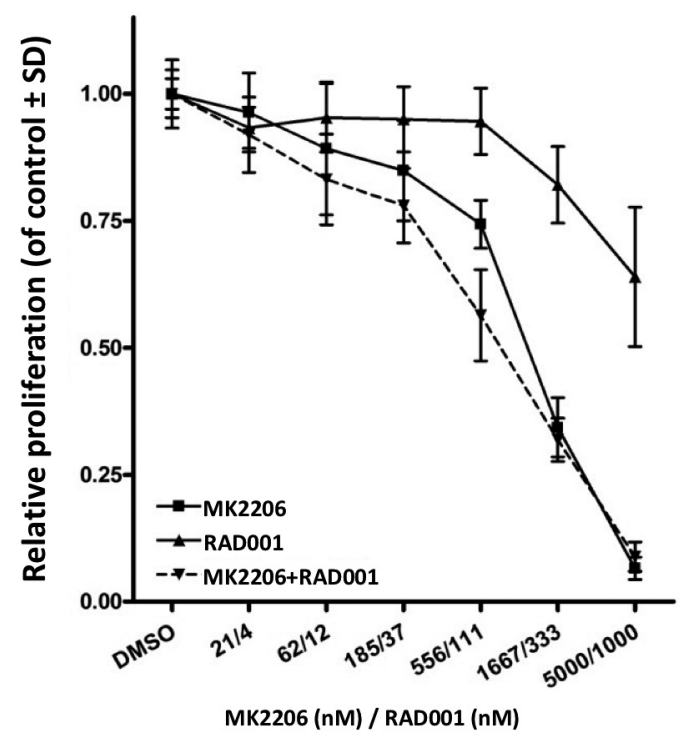

B

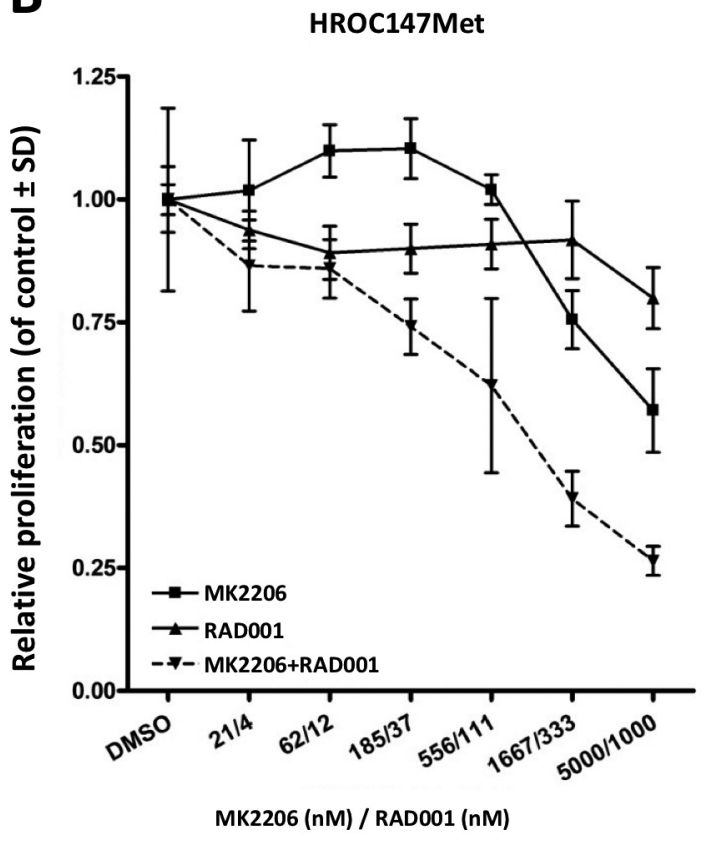

D

HROC277Met2

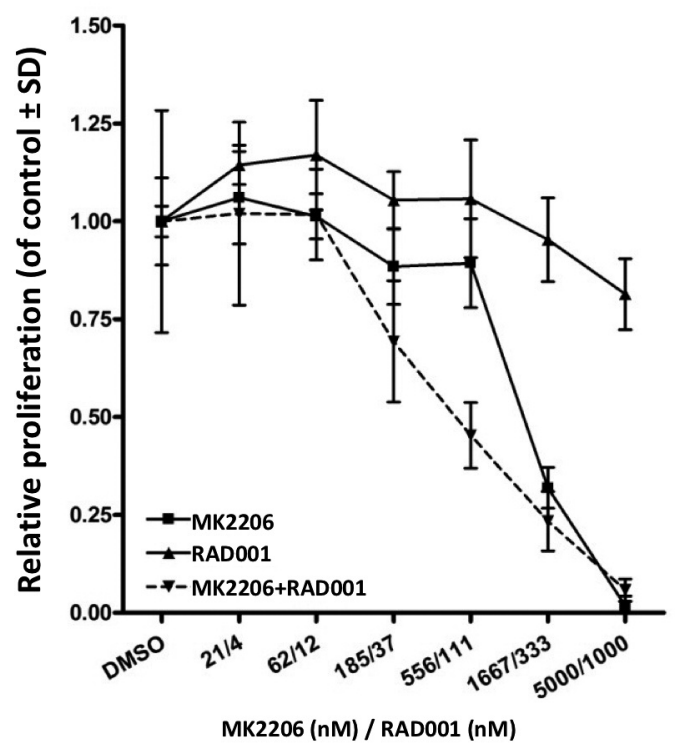

Figure 4. Continued inhibitors, which was proven to be superior to other combined treatment regimes in our previous studies $(18,34-$ 36). In clinical practice, targeted therapy is usually employed after identification of certain genetic markers, which make the tumour likely to respond to treatment. However, in this study, we deliberately chose an experimental approach identifying susceptible CRC cell lines through cell viability assays and analysing the effects of the treatment on cellular signalling at the protein level.

As expected, the tested CRC cells exhibited a great degree of heterogeneity, ranging from strong synergistic effects and inhibition of growth to almost complete upfront resistance. 
E
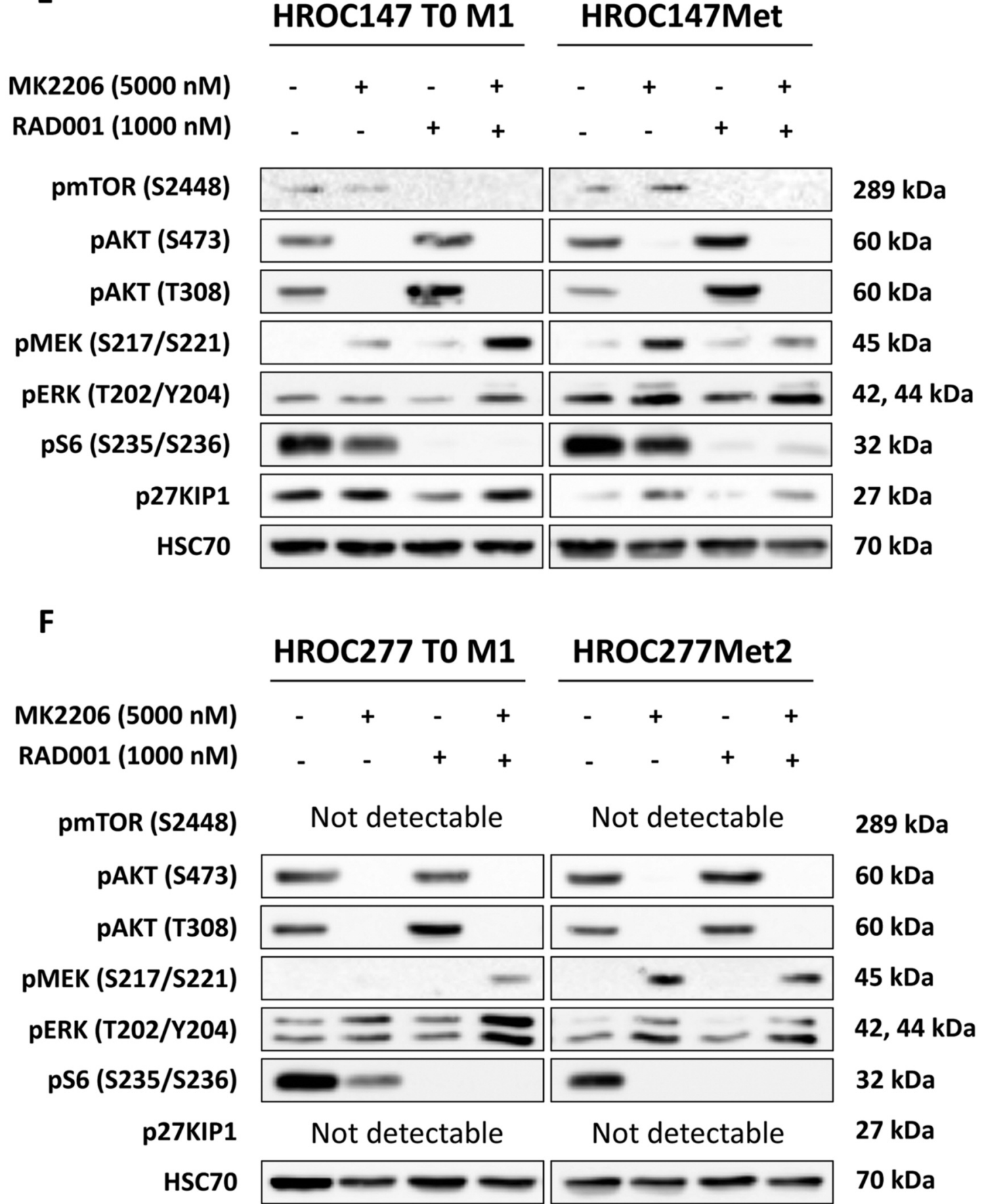

Figure 4. Cell lines from primary tumour and liver metastases from the same patient showed different responses to inhibition of AKT serine/threonine kinase (AKT) and mammalian target of rapamycin (mTOR). HROC147 TO M1 (A), HROC147Met (B), HROC277 TO M1 (C) and HROC277Met2 cells (D) were seeded into 96-well plates and allowed to attach overnight. Cells were then incubated for $72 \mathrm{~h}$ in the presence of increasing concentrations of either AKT inhibitor MK2206, mTOR inhibitor RAD001 or their combination in a fixed ratio (5:1 MK2206/RAD001). Control cells were treated with vehicle dimethyl sulfoxide only. BrdU ELISA assays were performed. Data are the mean sstandard deviation (SD). The exact combination index values and fractional effects are listed in Table I. Lysates were prepared of HROC147 cells (E) and HROC277 cells (F) treated with 5,000 nM MK2206, 1,000 nM RAD001, alone and in combination for $24 \mathrm{~h}$, and were subjected to western blot analysis of the activation/phosphorylation ( $p$ ) of phosphatidylinositol-3-kinase/AKT/mammalian target of rapamycin (PI3K/AKT/mTOR) and rat sarcoma/rapidly accelerated fibrosarcoma/mitogenactivated protein kinase kinaselextracellular signal-regulated kinase (RAS/RAF/MEK/ERK) signalling pathway proteins. Housekeeping protein heatshock cognate $71 \mathrm{kDa}$ protein (HSC70) was used as a loading control. DMSO: Dimethyl sulfoxide; p27KIP1: cyclin-dependent kinase inhibitor 1B. 
A

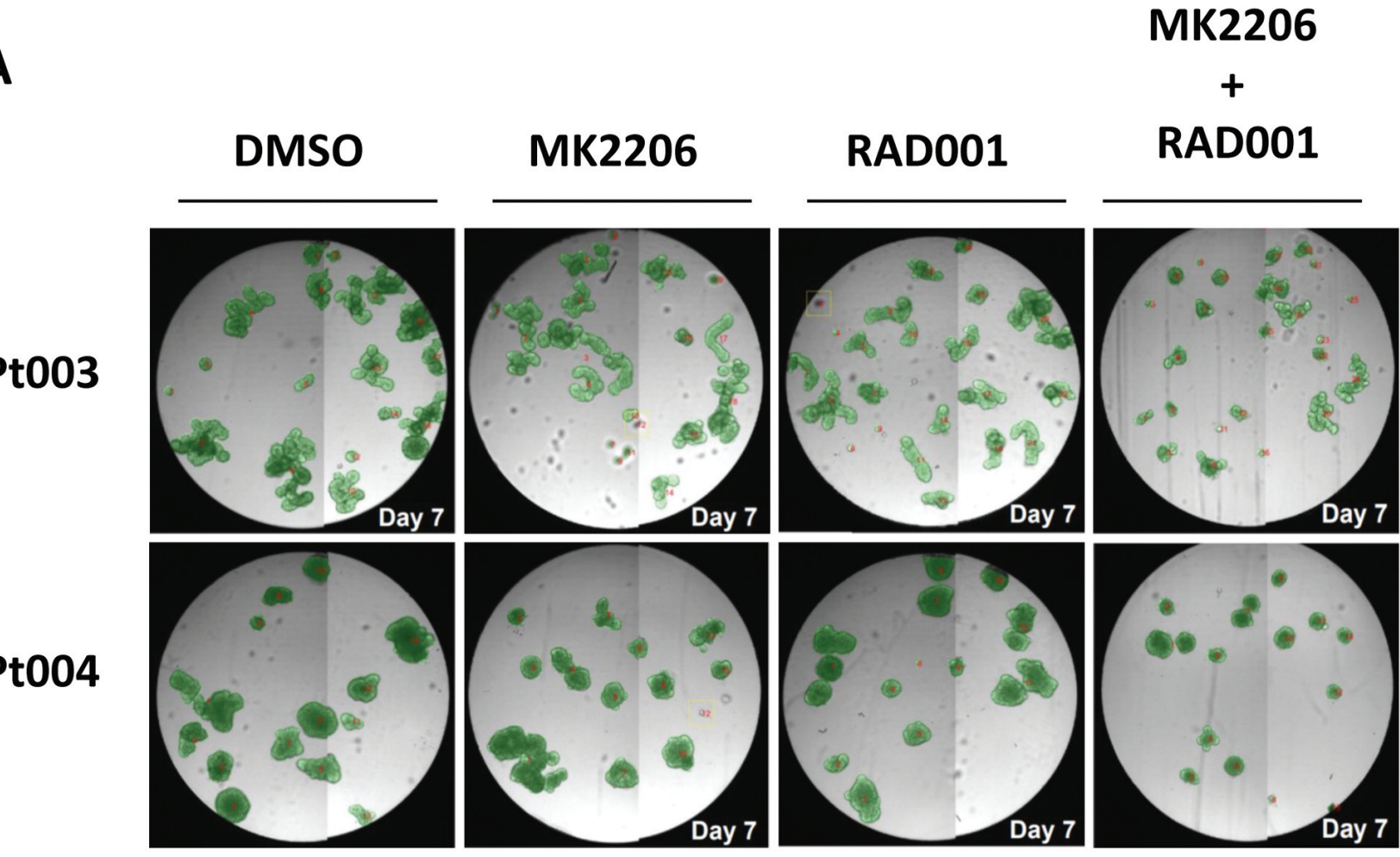

B

Primary CRC samples

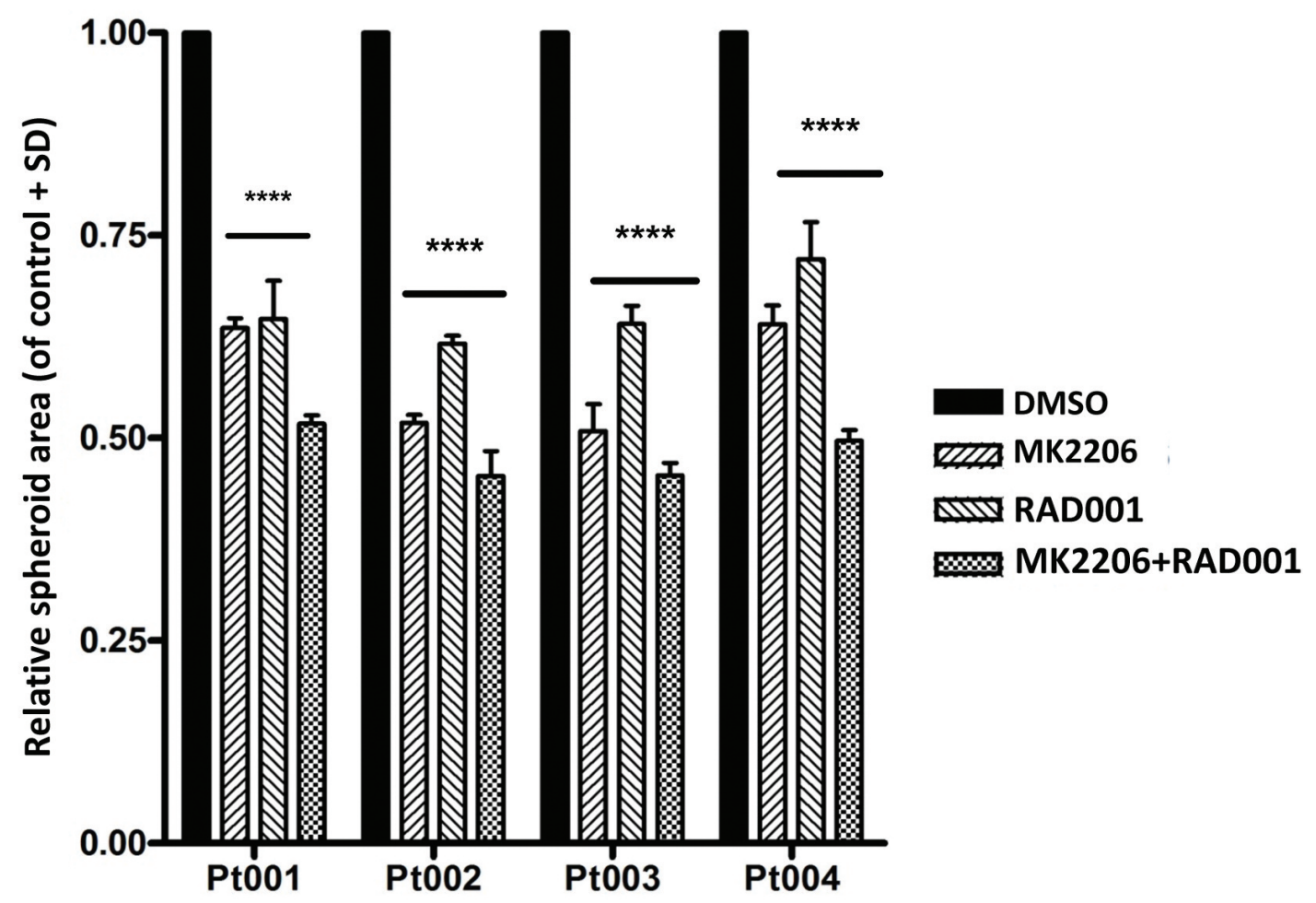



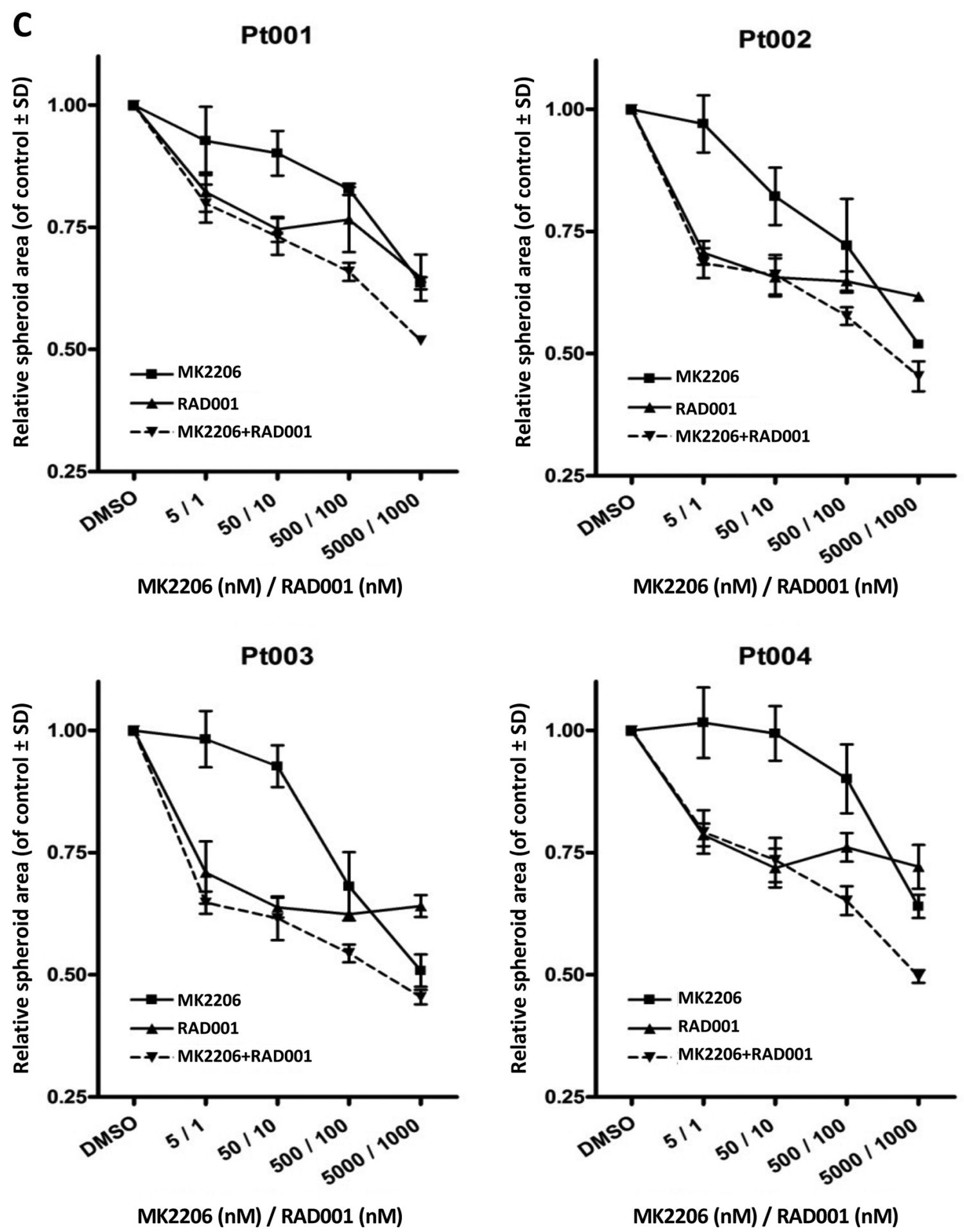

Figure 5. Sensitivity of $3 D$ cell cultures of primary colorectal carcinoma (CRC) samples to inhibition of AKT serinelthreonine kinase (AKT) and mammalian target of rapamycin (mTOR). Primary CRC samples of four different patients (Pt001-Pt004) were excised during surgery, processed and embedded in matrixbased $3 D$ cell culture for spheroid formation. A: Representative images of three-dimensional matrix-based cell culture of primary CRC samples derived from patient 3 (Pt003) and 4 (Pt004) during in vitro treatment with AKT inhibitor MK2206 and mTOR inhibitor RAD001. The drugs were delivered as drugeluting beads inside the matrix. B: The effect of treatment of patient-derived CRC spheroids with 5,000 nM MK2206, 1,000 nM RAD001, alone and in

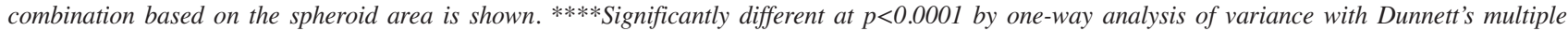
comparisons test. C: The effect of treatment of patient-derived CRC spheroids with MK2206, RAD001 or their combination (ratio 5:1) ranging from 5 nM to 5,000 nM MK2206. Data are the mean \pm standard deviation (SD). The exact combination index values and fractional effects are listed in Table II. 
Table II. Tabular view of the total doses of AKT serine/threonine kinase (AKT) inhibitor MK2206 and mammalian target of rapamycin (mTOR) inhibitor RADOO1 used, the fractional effect on proliferation, and the resulting combination index (CI) according to the Chou and Talalay method for primary patient samples studied. The CI values were determined using CompuSyn software (ComboSyn Inc., Paramus, NJ, USA). Pt001: Patient 1. Pt002: patient 2. Pt003: patient 3. Pt004: patient 4.

\begin{tabular}{cccc}
\hline & $\begin{array}{c}\text { Total dose of } \\
\text { MK2206/ } \\
\text { RAD001, nM }\end{array}$ & $\begin{array}{c}\text { Fractional } \\
\text { effect }\end{array}$ & $\begin{array}{c}\text { Combination } \\
\text { index }\end{array}$ \\
\hline Pt001 & $5 / 1$ & 0.20 & 0.35 \\
& $50 / 10$ & 0.27 & 0.16 \\
Pt002 & $500 / 100$ & 0.34 & 0.15 \\
& $5,000 / 1,000$ & 0.48 & 0.11 \\
& $5 / 1$ & 0.31 & 0.33 \\
Pt003 & $50 / 10$ & 0.34 & 0.48 \\
& $500 / 100$ & 0.42 & 0.25 \\
& $5,000 / 1,000$ & 0.55 & 0.85 \\
Pt004 & $5 / 1$ & 0.35 & 0.02 \\
& $50 / 10$ & 0.38 & 0.04 \\
& $500 / 100$ & 0.46 & 0.19 \\
& $5,000 / 1,000$ & 0.55 & 1.07 \\
& $5 / 1$ & 0.21 & 3.11 \\
& $50 / 10$ & 0.27 & 0.08 \\
& $500 / 100$ & 0.35 & 0.24 \\
& $5,000 / 1,000$ & 0.50 & 1.67 \\
\hline
\end{tabular}

Furthermore, HROC147 T0 M1 and HROC147Met cells, being derived from the primary lesion and liver metastasis of the same patient, respectively, reacted differently to combined treatment. Interestingly, the metastasis was far more affected by inhibition of AKT and mTOR than the primary tumour. Consequently, response to treatment in patients may differ between the primary tumour and metastasis, with the metastasis being sensitive to combinatorial treatment with AKT and mTOR inhibitors, even if the primary tumour is not affected.

It has been described that tumour signalling not only varies between different patients, but also within each individual tumour (22). High mutation rates and genomic instability quickly generate large numbers of different iterations of the initial tumour cells, the fittest of which will then expand to form different subpopulations; a phenomenon that has previously been described as "intra-tumoural heterogeneity" (37). This is especially true comparing different tumour sites, e.g. primary lesion and metastasis. Gerlinger et al. demonstrated that up to $69 \%$ of somatic mutations in renal cell carcinoma are not shared across all tumour sites, highlighting the concept of branched evolutionary tumour growth (38). Kreso et al. demonstrated that cell activity and sensitivity to treatment in CRC samples showed a high degree of variability while mutational status and DNA copy-number alteration remained after serial transplantation into mice (39).
Nonetheless, the emerging concept of intra-tumoural heterogeneity makes the choice of the correct kinase inhibitor therapy for any given tumour inherently difficult, since each tumour may already contain subpopulations of cells resistant to any possible drug. A combination of kinase inhibitors will be necessary to maintain inhibition of key pathways, while also blocking possible escape routes (5). Combined inhibition of AKT and mTOR represents one such approach, as it inactivates AKT, as the central element of the PI3K/AKT/mTOR axis, while simultaneously blocking feedback mechanisms through mTOR, which would otherwise restore part of the pathway's activation (17). It therefore provides a more lasting and thorough inactivation of the PI3K/AKT/mTOR axis than any single drug alone, as also shown in other cancer entities by our group in the past $(18,34-36,40)$. One major concern arising from the experimental analysis of signalling in CRC cells after combined treatment with AKT and mTOR inhibitors is the up-regulation of phosphorylated MEK in all CRC cell lines analysed. This may mean that activation of MEK leads to unwanted proliferation in MK2206/RAD001-treated CRC cells. Indeed, up-regulation of phosphorylated MEK has been reported before in cholangiocarcinoma cell lines after AKT/mTOR inhibition (32). Moreover, dual treatment with AKT and MEK inhibitors showed synergistic effects in cholangiocarcinoma cell lines and acquired resistance to MEK inhibition was able to be reversed using a dual targeting approach of either MEK/AKT or MEK/mTOR (32). Consequently, a MEK inhibitor should be analysed in addition to AKT and mTOR inhibitors for CRC treatment. We recently demonstrated that triple treatment with AKT, mTOR and MEK inhibitors showed synergistic effects, compared to dual targeting of $\mathrm{AKT} / \mathrm{mTOR}$, on the proliferation of malignant peripheral nerve sheath tumours (36). A triple targeting approach of MEK in addition to AKT and mTOR exhibited synergistic activity in preclinical melanoma models with cells harbouring a NRAS mutation (41).

Profiling of tumour samples for specific biomarkers to predict sensitivity to certain treatment regimens is already commonplace in clinical practice today for many different types of cancer $(27,42)$. As sequencing technology advances and new methods such as liquid biopsy (43) facilitate sample acquisition, genetic profiling of individual tumours is should further gain relevance for personalized cancer therapy in the future (44). However, the heterogeneity of cancer cells currently limits the validity of biomarkers as being representative of the entire tumour cell collective and severely limits the benefit of modern targeted therapy regimens. Patient-derived organoids were presented as a potential approach to predicting treatment response in patients. A study by Ooft et al. was able to prospectively predict treatment response to irinotecan-based chemotherapy regimens in eight out of 10 metastatic CRC cases analysed. 
Despite the promising results with respect to the prediction of irinotecan-based response rates in patients, the authors failed to successfully predict sensitivity towards oxaliplatinbased therapy (45). Still, the data on irinotecan-based treatments provided a foundation for further trials. Considering the possibility to facilitate clinical decision making and therefore improve the response rates, patientderived organoids should be further examined.

Combined inhibition of AKT and mTOR may prove useful as part of a comprehensive personalized treatment regimen for individual colorectal tumours and its efficacy in vivo should be further explored. Although we detected a significant difference between the treatment group and the control littermates in our xenotransplantation mouse model, there was no significant effect on overall survival of the mice, although we had observed that in our previous xenotransplantation mouse models after combinatorial treatment of a hepatocellular carcinoma cell line (34) and cholangiocarcinoma cell line (18) with MK2206 and RAD001. Further analysis of the HROC80 T1 M1 patientderived xenografts suggests a rapid resistance, after less than 30 days, to treatment with AKT and mTOR inhibitors. Interestingly, the resistance was presumably not mediated by up-regulation of the RAS/RAF/MEK/MAPK pathway (as our western blot analysis indicated) which has been reported in the past after AKT and mTOR inhibition in primary prostate cancer samples (46). We therefore conclude that resistance may be due to a restoration of the initial levels of phospho-AKT and phospho-S6 rather than a compensatory activation of other pathways e.g. RAS/RAF/MEK/ERK pathway. A possible explanation of resistance may be the increasing size of the tumours and therefore a progressive degree of tumour heterogeneity and higher rate of treatment failure as described in the past (47).

Despite the observed resistance after treatment of the PDX in vivo, tumour spheroid experiments are an interesting empirical and animal-free concept. Tumour spheroid experiments may complement genetic profiling to determine effective treatment strategies and provide information about potential escape mechanisms of cancer cells before they manifest in patients during treatment.

\section{Conclusion}

We have shown that combined inhibition of AKT and mTOR is highly efficacious and synergistic in vitro in many, but not all, analysed CRC cell lines. Response to treatment varied, not only between cells from different patients, but also between primary tumours and their metastases. Primary CRC samples obtained during surgery and grown as tumour spheroids exhibited similar behaviour when treated with the same combination of drugs. Combination of AKT and mTOR inhibitors should be explored in future studies and may be valuable as part of a comprehensive kinase inhibitor treatment regime in patients with CRC. Tumour spheroid assays as a means of pre-therapeutic drug testing may complement genetic profiling of tumour cells for the generation of personalized treatment regimens.

\section{Conflicts of Interest}

The Authors declare no conflicts of interest.

\section{Authors' Contributions}

D.N., M.L., J.R.I., O.T. and M.J. designed the study. D.N., C.S.M., D.J.S, M.L., G.H., A.M., J.S., P.E. and A.B. performed the experiments and interpreted the experimental findings. D.N., D.J.S. and M.J. drafted and wrote the final version of the article. All Authors read and approved the final article.

\section{Acknowledgements}

The Authors are grateful to Bettina Bettin (University Medical Center Eppendorf, Institute of Biochemistry and Signal Transduction) for excellent technical assistance.

\section{References}

1 Bray F, Ferlay J, Soerjomataram I, Siegel RL, Torre LA and Jemal A: Global cancer statistics 2018: Globocan estimates of incidence and mortality worldwide for 36 cancers in 185 countries. CA Cancer J Clin 68(6): 394-424, 2018. PMID: 30207593. DOI: $10.3322 /$ caac.21492

2 Muto T, Bussey HJ and Morson BC: The evolution of cancer of the colon and rectum. Cancer 36(6): 2251-2270, 1975. PMID: 1203876. DOI: $10.1002 /$ cncr.2820360944

3 De Rosa M, Pace U, Rega D, Costabile V, Duraturo F, Izzo P and Delrio P: Genetics, diagnosis and management of colorectal cancer (Review). Oncol Rep 34(3): 1087-1096, 2015. PMID: 26151224. DOI: $10.3892 /$ or.2015.4108

4 Dimitroulis D, Nikiteas N, Troupis T, Patsouras D, Skandalakis $\mathrm{P}$ and Kouraklis G: Role of surgery in colorectal liver metastases: Too early or too late? World J Gastroenterol 16(28): 3484-3490, 2010. PMID: 20653056. DOI: 10.3748/wjg.v16. i28.3484

5 Tolcher AW, Peng W and Calvo E: Rational approaches for combination therapy strategies targeting the MAP kinase pathway in solid tumors. Mol Cancer Ther 17(1): 3-16, 2018. PMID: 29295962. DOI: 10.1158/1535-7163.MCT-17-0349

6 Edwards MS, Chadda SD, Zhao Z, Barber BL and Sykes DP: A systematic review of treatment guidelines for metastatic colorectal cancer. Colorectal Dis 14(2): e31-e47, 2012. PMID: 21848897. DOI: 10.1111/j.1463-1318.2011.02765.x

7 Sonbol MB, Mountjoy LJ, Firwana B, Liu AJ, Almader-Douglas D, Mody K, Hubbard J, Borad M, Ahn DH, Murad MH and Bekaii-Saab T: The role of maintenance strategies in metastatic colorectal cancer: A systematic review and network metaanalysis of randomized clinical trials. JAMA Oncol 6(3): e194489, 2020. PMID: 31855256. DOI: 10.1001/jamaoncol. 2019.4489 
8 Janku F, Yap TA and Meric-Bernstam F: Targeting the PI3K pathway in cancer: Are we making headway? Nat Rev Clin Oncol 15(5): 273-291, 2018. PMID: 29508857. DOI: 10.1038/nrclinonc.2018.28

9 Johnson SM, Gulhati P, Rampy BA, Han Y, Rychahou PG, Doan HQ, Weiss HL and Evers BM: Novel expression patterns of $\mathrm{PI} 3 \mathrm{~K} / \mathrm{Akt} / \mathrm{mTOR}$ signaling pathway components in colorectal cancer. J Am Coll Surg 210(5): 767-76, 776-8, 2010. PMID: 20421047. DOI: 10.1016/j.jamcollsurg.2009.12.008

10 Samuels Y, Wang Z, Bardelli A, Silliman N, Ptak J, Szabo S, Yan H, Gazdar A, Powell SM, Riggins GJ, Willson JK, Markowitz S, Kinzler KW, Vogelstein B and Velculescu VE: High frequency of mutations of the PIK3CA gene in human cancers. Science 304(5670): 554, 2004. PMID: 15016963. DOI: 10.1126/science. 1096502

11 Markowitz SD and Bertagnolli MM: Molecular origins of cancer: Molecular basis of colorectal cancer. N Engl J Med 361(25): 2449-2460, 2009. PMID: 20018966. DOI: 10.1056/ NEJMra0804588

12 Osaki M, Oshimura $\mathrm{M}$ and Ito H: PI3K-Akt pathway: Its functions and alterations in human cancer. Apoptosis 9(6): 667676, 2004. PMID: 15505410. DOI: 10.1023/B:APPT. 0000045801.15585.dd

13 Itoh N, Semba S, Ito M, Takeda H, Kawata S and Yamakawa M: Phosphorylation of $\mathrm{Akt} / \mathrm{PKB}$ is required for suppression of cancer cell apoptosis and tumor progression in human colorectal carcinoma. Cancer 94(12): 3127-3134, 2002. PMID: 12115344. DOI: $10.1002 /$ cncr.10591

14 Roy HK, Olusola BF, Clemens DL, Karolski WJ, Ratashak A, Lynch HT and Smyrk TC: AKT proto-oncogene overexpression is an early event during sporadic colon carcinogenesis. Carcinogenesis 23(1): 201-205, 2002. PMID: 11756242. DOI: 10.1093/carcin/23.1.201

15 Yang H, Rudge DG, Koos JD, Vaidialingam B, Yang HJ and Pavletich NP: mTOR kinase structure, mechanism and regulation. Nature 497(7448): 217-223, 2013. PMID: 23636326. DOI: $10.1038 /$ nature 12122

16 Manning BD and Toker A: AKT/PKB signaling: Navigating the network. Cell 169(3): 381-405, 2017. PMID: 28431241. DOI: 10.1016/j.cell.2017.04.001

17 O'Reilly KE, Rojo F, She QB, Solit D, Mills GB, Smith D, Lane H, Hofmann F, Hicklin DJ, Ludwig DL, Baselga J and Rosen N: mTOR inhibition induces upstream receptor tyrosine kinase signaling and activates Akt. Cancer Res 66(3): 1500-1508, 2006. PMID: 16452206. DOI: 10.1158/0008-5472.CAN-05-2925

18 Ewald F, Grabinski N, Grottke A, Windhorst S, Nörz D, Carstensen L, Staufer K, Hofmann BT, Diehl F, David K, Schumacher U, Nashan B and Jücker M: Combined targeting of AKT and mTOR using MK-2206 and RAD001 is synergistic in the treatment of cholangiocarcinoma. Int J Cancer 133(9): 20652076, 2013. PMID: 23588885. DOI: 10.1002/ijc.28214

19 Lu Q, Wang J, Yu G, Guo T, Hu C and Ren P: Expression and clinical significance of mammalian target of rapamycin/P70 ribosomal protein S6 kinase signaling pathway in human colorectal carcinoma tissue. Oncol Lett 10(1): 277-282, 2015. PMID: 26171014. DOI: 10.3892/ol.2015.3228

20 Wiesweg M, Reis H, Köster T, Goetz M, Worm K, Herold T, Paul A, Dechêne A, Schumacher B, Markus P, Virchow I, Kostbade K, Wolf N, Zaun G, Metzenmacher M, Schmid KW, Schuler M and Kasper S: Phosphorylation of p70 ribosomal protein S6 kinase $\beta-1$ is an independent prognostic parameter in metastatic colorectal cancer. Clin Colorectal Cancer 17(2): e331e352, 2018. PMID: 29526493. DOI: 10.1016/j.clcc.2018.02.003

21 Narayanankutty A: PI3K/ Akt/ mTOR pathway as a therapeutic target for colorectal cancer: A review of preclinical and clinical evidence. Curr Drug Targets 20(12): 1217-1226, 2019. PMID: 31215384. DOI: $10.2174 / 1389450120666190618123846$

22 Huang M, Shen A, Ding J and Geng M: Molecularly targeted cancer therapy: Some lessons from the past decade. Trends Pharmacol Sci 35(1): 41-50, 2014. PMID: 24361003. DOI: 10.1016/j.tips.2013.11.004

23 Zanoni M, Piccinini F, Arienti C, Zamagni A, Santi S, Polico R, Bevilacqua A and Tesei A: 3D tumor spheroid models for in vitro therapeutic screening: A systematic approach to enhance the biological relevance of data obtained. Sci Rep 6: 19103, 2016. PMID: 26752500. DOI: 10.1038/srep19103

24 Imamura Y, Mukohara T, Shimono Y, Funakoshi Y, Chayahara N, Toyoda M, Kiyota N, Takao S, Kono S, Nakatsura T and Minami H: Comparison of 2D- and 3D-culture models as drugtesting platforms in breast cancer. Oncol Rep 33(4): 1837-1843, 2015. PMID: 25634491. DOI: 10.3892/or.2015.3767

25 Jeppesen M, Hagel G, Glenthoj A, Vainer B, Ibsen P, Harling H, Thastrup O, Jørgensen LN and Thastrup J: Short-term spheroid culture of primary colorectal cancer cells as an in vitro model for personalizing cancer medicine. PLoS One 12(9): e0183074, 2017. PMID: 28877221. DOI: 10.1371/journal.pone.0183074

26 Linnebacher M, Maletzki C, Ostwald C, Klier U, Krohn M, Klar E and Prall F: Cryopreservation of human colorectal carcinomas prior to xenografting. BMC Cancer 10: 362, 2010. PMID: 20615215. DOI: $10.1186 / 1471-2407-10-362$

27 Medico E, Russo M, Picco G, Cancelliere C, Valtorta E, Corti G, Buscarino M, Isella C, Lamba S, Martinoglio B, Veronese S, Siena S, Sartore-Bianchi A, Beccuti M, Mottolese M, Linnebacher M, Cordero F, Di Nicolantonio F and Bardelli A: The molecular landscape of colorectal cancer cell lines unveils clinically actionable kinase targets. Nat Commun 6: 7002, 2015. PMID: 25926053. DOI: 10.1038/ncomms8002

28 Kondo J, Endo H, Okuyama H, Ishikawa O, Iishi H, Tsujii M, Ohue $\mathrm{M}$ and Inoue $\mathrm{M}$ : Retaining cell-cell contact enables preparation and culture of spheroids composed of pure primary cancer cells from colorectal cancer. Proc Natl Acad Sci USA 108(15): 6235-6240, 2011. PMID: 21444794. DOI: 10.1073/ pnas. 1015938108

29 Mullins CS, Micheel B, Matschos S, Leuchter M, Bürtin F, Krohn M, Hühns M, Klar E, Prall F and Linnebacher M: Integrated biobanking and tumor model establishment of human colorectal carcinoma provides excellent tools for preclinical research. Cancers (Basel) 11(10): , 2019. PMID: 31601052. DOI: $10.3390 /$ cancers 11101520

30 Grabinski N and Ewald F: Ibrutinib (ImbruvicaTM) potently inhibits ErbB receptor phosphorylation and cell viability of ErbB2-positive breast cancer cells. Invest New Drugs 32(6): 1096-1104, 2014. PMID: 25081321. DOI: 10.1007/s10637-0140141-2

31 Grabinski N, Bartkowiak K, Grupp K, Brandt B, Pantel K and Jücker M: Distinct functional roles of Akt isoforms for proliferation, survival, migration and EGF-mediated signalling in lung cancer derived disseminated tumor cells. Cell Signal 23(12): 1952-1960, 2011. PMID: 21777670. DOI: $10.1016 /$ j.cellsig.2011.07.003 
32 Ewald F, Norz D, Grottke A, Hofmann BT, Nashan B and Jucker M: Dual inhibition of PI3K-AKT-mTOR and RAF-MEK-ERK signaling is synergistic in cholangiocarcinoma and reverses acquired resistance to MEK inhibitors. Invest New Drugs 32(6): 1144-1154, 2014. PMID: 25152244. DOI: 10.1007/s10637-0140149-7

33 Chou TC: Theoretical basis, experimental design, and computerized simulation of synergism and antagonism in drug combination studies. Pharmacol Rev 58(3): 621-681, 2006. PMID: 16968952. DOI: $10.1124 /$ pr.58.3.10

34 Grabinski N, Ewald F, Hofmann BT, Staufer K, Schumacher U, Nashan B and Jücker M: Combined targeting of AKT and mTOR synergistically inhibits proliferation of hepatocellular carcinoma cells. Mol Cancer 11: 85, 2012. PMID: 23167739. DOI: $10.1186 / 1476-4598-11-85$

35 Ewald F, Nörz D, Grottke A, Bach J, Herzberger C, Hofmann BT, Nashan B and Jücker M: Vertical targeting of AKT and mTOR as well as dual targeting of AKT and MEK signaling is synergistic in hepatocellular carcinoma. J Cancer 6(12): 11951205, 2015. PMID: 26535060. DOI: 10.7150/jca.12452

36 Schulte A, Ewald F, Spyra M, Smit DJ, Jiang W, Salamon J, Jücker M and Mautner VF: Combined targeting of AKT and mTOR inhibits proliferation of human NF1-associated malignant peripheral nerve sheath tumour cells in vitro but not in a xenograft mouse model in vivo. Int J Mol Sci 21(4): 1548, 2020. PMID: 32102484. DOI: 10.3390/ijms21041548

37 Marusyk A, Almendro $\mathrm{V}$ and Polyak K: Intra-tumour heterogeneity: A looking glass for cancer?. Nat Rev Cancer 12(5): 323-334, 2012. PMID: 22513401. DOI: $10.1038 / \mathrm{nrc} 3261$

38 Gerlinger M, Rowan AJ, Horswell S, Math M, Larkin J, Endesfelder D, Gronroos E, Martinez P, Matthews N, Stewart A, Tarpey P, Varela I, Phillimore B, Begum S, McDonald NQ, Butler A, Jones D, Raine K, Latimer C, Santos CR, Nohadani M, Eklund AC, Spencer-Dene B, Clark G, Pickering L, Stamp G, Gore M, Szallasi Z, Downward J, Futreal PA and Swanton C: Intratumor heterogeneity and branched evolution revealed by multiregion sequencing. N Engl J Med 366(10): 883-892, 2012. PMID: 22397650. DOI: 10.1056/NEJMoa1113205

39 Kreso A, O'Brien CA, van Galen P, Gan OI, Notta F, Brown AM, Ng K, Ma J, Wienholds E, Dunant C, Pollett A, Gallinger S, McPherson J, Mullighan CG, Shibata D and Dick JE: Variable clonal repopulation dynamics influence chemotherapy response in colorectal cancer. Science 339(6119): 543-548, 2013. PMID: 23239622. DOI: $10.1126 /$ science. 1227670

40 Smit DJ, Cayrefourcq L, Haider MT, Hinz N, Pantel K, AlixPanabières $\mathrm{C}$ and Jücker M: High sensitivity of circulating tumor cells derived from a colorectal cancer patient for dual inhibition with AKT and mTOR inhibitors. Cells 9(9): 2129, 2020. PMID: 32962206. DOI: 10.3390/cells9092129
41 Posch C, Moslehi H, Feeney L, Green GA, Ebaee A, Feichtenschlager V, Chong K, Peng L, Dimon MT, Phillips T, Daud AI, McCalmont TH, LeBoit PE and Ortiz-Urda S: Combined targeting of MEK and PI3K/mTOR effector pathways is necessary to effectively inhibit NRAS mutant melanoma in vitro and in vivo. Proc Natl Acad Sci USA 110(10): 4015-4020, 2013. PMID: 23431193. DOI: 10.1073/pnas.1216013110

42 Cheng L, Lopez-Beltran A, Massari F, MacLennan GT and Montironi R: Molecular testing for BRAF mutations to inform melanoma treatment decisions: A move toward precision medicine. Mod Pathol 31(1): 24-38, 2018. PMID: 29148538. DOI: $10.1038 /$ modpathol.2017.104

43 Pantel K and Alix-Panabières C: Liquid biopsy and minimal residual disease - latest advances and implications for cure. Nat Rev Clin Oncol 16(7): 409-424, 2019. PMID: 30796368. DOI: 10.1038/s41571-019-0187-3

44 Alix-Panabières $\mathrm{C}$ and Pantel K: Clinical applications of circulating tumor cells and circulating tumor DNA as liquid biopsy. Cancer Discov 6(5): 479-491, 2016. PMID: 26969689. DOI: $10.1158 / 2159-8290 . C D-15-1483$

45 Ooft SN, Weeber F, Dijkstra KK, McLean CM, Kaing S, van Werkhoven E, Schipper L, Hoes L, Vis DJ, van de Haar J, Prevoo W, Snaebjornsson P, van der Velden D, Klein M, Chalabi M, Boot H, van Leerdam M, Bloemendal HJ, Beerepoot LV, Wessels L, Cuppen E, Clevers H and Voest EE: Patient-derived organoids can predict response to chemotherapy in metastatic colorectal cancer patients. Sci Transl Med 11(513): 2019. PMID: 31597751. DOI: $10.1126 /$ scitranslmed aay 2574

46 Butler DE, Marlein C, Walker HF, Frame FM, Mann VM, Simms MS, Davies BR, Collins AT and Maitland NJ: Inhibition of the PI3K/AKT/mTOR pathway activates autophagy and compensatory Ras/Raf/MEK/ERK signalling in prostate cancer. Oncotarget 8(34): 56698-56713, 2017. PMID: 28915623. DOI: 10.18632/oncotarget. 18082

47 Yaes RJ: Tumor heterogeneity, tumor size, and radioresistance. Int J Radiat Oncol Biol Phys 17(5): 993-1005, 1989. PMID: 2808062. DOI: 10.1016/0360-3016(89)90147-8

Received March 12, 2021

Revised March 28, 2021

Accepted March 31, 2021 